\title{
Delivery of drugs using tamarind gum and modified tamarind gum: A review
}

\author{
Kailas K. Mali', Shashikant C Dhawale ${ }^{2}$, Remeth J Dias ${ }^{3}$, Vishwajeet S Ghorpade ${ }^{4}$ \\ ${ }^{1}$ Department of Pharmaceutics, Adarsh College of Pharmacy, Vita-415 311, Sangali, \\ Maharashtra, India \\ ${ }^{2}$ Department of Pharmacology, School of Pharmacy, SRTM University, Maharashtra, India \\ ${ }^{3}$ Department of Pharmacy, Government Polytechnic, Maharashtra, India \\ ${ }^{4}$ Department of Pharmaceutics, Sanjay Ghodawat University, School of Pharmaceutical \\ Sciences, SGU Campus, Atigare, Kolhapur, Maharashtra, India
}

\begin{abstract}
Tamarind seed polysaccharide is an emerging excipient, which is being used and investigated for the preparation of various dosage forms. Functionalization of tamarind gum (TG) enhances the properties of native tamarind polysaccharide like degradability, hydration, viscosity and swelling. Due to these excellent properties, researchers investigated the application of modified TG in various drug delivery systems. TG and modified TG are found to be appropriate for the designing of oral, nasal, ophthalmic, colonic and topical drug delivery systems. Moreover, they are used in the preparation of hydrogel-based drug delivery systems and novel drug delivery systems such as nanoparticles. Considering the above facts, additional research work is required to confirm the pharmaceutical uses of TG and modified TG in drug delivery. The current review deals with a comprehensive and valuable discussion on pharmaceutical applications of TG and modified TG.
\end{abstract}

Received: 10 July 2018, Accepted: 28 December 2018

Key Words: Carboxymethyltamarind gum, modified tamarind gum, tamarind gum.

Corresponding Author: Kailas K. Mali, Department of Pharmaceutics, Adarsh College of Pharmacy, Vita-415311, Sangali, Maharashtra, India, Tel.: +919552527353, E-mail: malikailas@gmail.com

Bulletin of Faculty of Pharmacy, Cairo University, ISSN: 1110-0931, Vol. 57, No. 1

\section{INTRODUCTION}

The attention towards polysaccharides of natural origin is constantly rising since past decade. The natural polysaccharides are widely used in the field of food technology, cosmetics, pharmaceuticals and biomedical sciences. Exploitation of new sources of polysaccharides of different origin is well documented in the literature ${ }^{[1]}$. They exhibit good mechanical properties and are widely used as fibers, films, adhesives, rheology modifiers, hydrogels, emulsifiers and drug delivery agents. Sodium alginate
$(\mathrm{SA})^{[2]}$, xanthan gum $(\mathrm{XG})^{[3]}$, guar gum, scleroglucan, and locust bean gums are some of the natural polysaccharides which are fueling the interest of the researchers dealing with the development of drug delivery systems ${ }^{[4]}$. The functional groups of polysaccharides have been explored for chemical modification to change their properties like solubility, swelling, viscosity, and degradation ${ }^{[5]}$. Some of the chemically modified derivatives of natural polysaccharides which are extensively used in drug delivery systems are given in (Table 1).

Table 1: Chemically modified natural polysaccharide

\begin{tabular}{|c|c|c|c|}
\hline Natural polysaccharide & Chemical modification & Name of derivative & Pharmaceutical application \\
\hline $\begin{array}{l}\text { Sodium } \\
\text { alginate }\end{array}$ & $\begin{array}{l}\text { Alkylation } \\
\text { Thiolation }\end{array}$ & $\begin{array}{l}\text { Alkyl-alginate } \\
\text { Thiolated alginate }\end{array}$ & $\begin{array}{l}\text { Release retardant }{ }^{[6]} \\
\text { Mucoadhesive delivery }{ }^{[7]}\end{array}$ \\
\hline Guar gum & $\begin{array}{l}\text { Carboxymethylation } \\
\text { Grafting }\end{array}$ & $\begin{array}{l}\text { Carboxymethyl guar gum } \\
\text { Polyacrylamide-guar gum }\end{array}$ & $\begin{array}{l}\text { Transdermal delivery }{ }^{[8]} \\
\text { GRDF }^{[9]} \\
\text { Hydrogel }^{[10]} \text { Matrix former } \\
\end{array}$ \\
\hline Chitosan & $\begin{array}{l}\text { Carboxymethylation sulfation } \\
\text { Thiolation }\end{array}$ & $\begin{array}{l}\text { Carboxymethyl chitosan } \\
\text { Thiolated chitosan }\end{array}$ & $\begin{array}{l}\text { Implant }^{[12]} \\
\text { Micro and Nanoparticles } \\
\end{array}$ \\
\hline Pectin & $\begin{array}{l}\text { Thiolation } \\
\text { Acetylation }\end{array}$ & $\begin{array}{l}\text { Thiolated pectin } \\
\text { Phenyl acetyl pecti }\end{array}$ & $\begin{array}{l}\text { Mucoadhesive delivery } \\
\text { Release retardant }{ }^{[15]}\end{array}$ \\
\hline Xanthan gum & $\begin{array}{l}\text { Carboxymethylation } \\
\text { Grafting }\end{array}$ & $\begin{array}{l}\text { Carboxymethyl xanthan } \\
\text { Acrylamide }\end{array}$ & $\begin{array}{l}\text { microparticles }{ }^{[16]} \\
\text { Controlled release }^{[17]}\end{array}$ \\
\hline
\end{tabular}




\section{TAMARIND GUM - A VERSATILE NATURAL} POLYSACCHARIDE

Tamarind (Tamarindus indica), usually known as Imli, is a member of the dicotyledonous family, Leguminosae. India produces about 0.3 million tons of tamarind yearly, of which the seed constitutes about $30-34 \%$ of the whole fruit. The potential for exporting tamarind from India in the past few years shows a good market for tamarind ${ }^{[18]}$. The seed comprises of the seed coat or testa $(20-30 \%)$ and the kernel or endosperm $(70-80 \%)$. It contains $67.1 \mathrm{~g} / \mathrm{Kg}$ crude fiber with a higher percentage of carbohydrate in the form of sugars ${ }^{[19]}$. Tamarind seed is the raw material used in the manufacture of tamarind seed kernel powder (TKP), polysaccharide, adhesive and tannin. The seeds are also used for other purposes and are presently gaining importance as an alternative source of protein, rich in some essential amino acids ${ }^{[18]}$.

\subsection{Chemistry and properties of Tamarind Gum}

Tamarind gum (TG) is obtained from the kernel of the seeds powder. Seeds contain $60-65 \%$ of a polysaccharide ${ }^{[20]}$. It is chemically galactoxyloglucan. TG is a polymer with the average molecular weight of 52350 Daltons. It consists of glucose, xylose and galactose in a molar ratio of $3: 2: 1^{[20,21]}$. The observed chain length of TG varies from 300-3000 glucose units ${ }^{[22]}$. The structure of TG polysaccharide is given in (Figure 1).

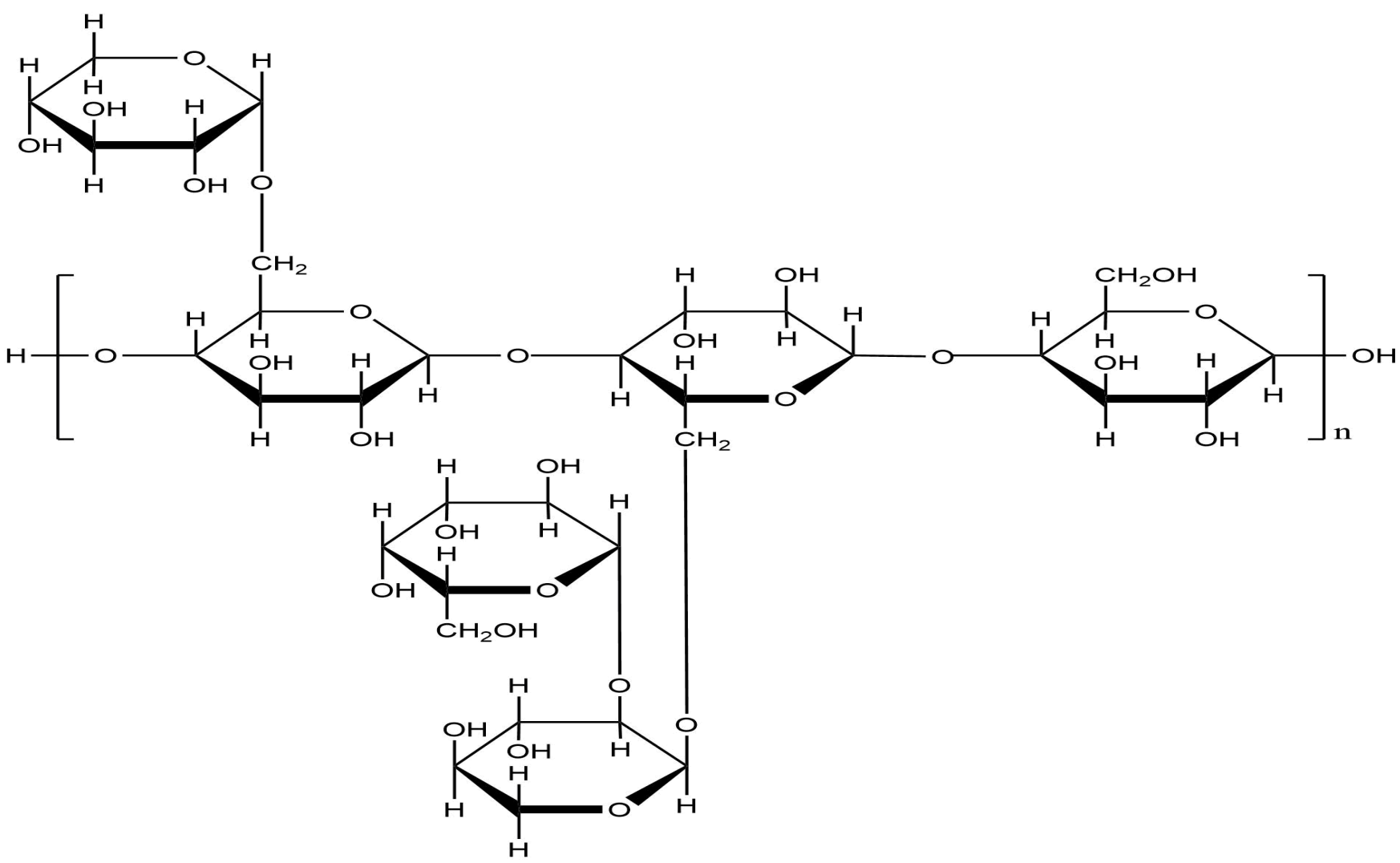

Fig. 1: Structure of $\mathrm{TG}^{[23]}$

TG is a neutral, nonionic and branched polysaccharide. It is insoluble in organic solvents ${ }^{[24]}$ and dispersible in hot water to form a highly viscous gel. TG possesses properties like high viscosity, broad $\mathrm{pH}$ tolerance, and adhesion ${ }^{[25]}$. It is non-carcinogenic ${ }^{[26]}$, non-toxic ${ }^{[27,28]}$, mucoadhesive ${ }^{[29,30]}$, biodegradable ${ }^{[31]}$ and biocompatible ${ }^{[32,33]}$ with high drug holding capacity ${ }^{[2]}$ and high thermal stability ${ }^{[34]}$. TG contains cellulose-like backbone that carries xylose and galactoxylose substituents, and chemical residues similar to mucin (MUC-1) and episialin ${ }^{[35]}$. TG is able to bind cell surface and intensify the contact between drugs and the adsorbing biological membrane due to similar nature to mucin ${ }^{[36]}$. It swells in water and forms a mucilaginous solution after heating, exhibiting a typical non-Newtonian rheological behavior and pseudoplastic properties ${ }^{[37]}$. TG has the capability to form gels in the presence of sugar ${ }^{[38]}$ or alcohol ${ }^{[39]}$ and can be used to form pectin like gels in jams, jellies and other preserves. Also, it has the capacity to form ion gel with bio-based ionic liquids ${ }^{[40]}$. It produces films with high tensile strength and flexibility ${ }^{[34]}$ which makes it a good excipient for ocular preparations. This film is transparent, nonhygroscopic, non-sticky and retains its form even on rough handling. Its Ferning pattern is similar to natural tear film ${ }^{[21]}$. TG is comparatively cheap, non-irritant, eco-friendly and non-polluting than other semisynthetic or synthetic polymers. Due to its distinct advantageous properties, TG is used as the polymer in the fields of cosmetic and food industry ${ }^{[4,19,21,41]}$. Recent studies showed that TG forms an excellent hydrogel by physical crosslinking, which makes it suitable for topical drug delivery ${ }^{[42,43]}$. 


\subsection{Isolation and purification of TG}

Various methods have been reported in the literature to separate gum from the tamarind seeds $s^{[4,21,44]}$. Initially, tamarind seeds are washed with water and heated to make outer coat brittle and friable. The seed coat is separated from the endosperm by crushing. The decorticated seed is powdered to obtain TKP. Thereafter, TKP is boiled with about 30-40 times its weight of $2 \% \mathrm{w} / \mathrm{v}$ citric acid for about 30-40 min with continuous stirring and kept for $12 \mathrm{~h}$ in order to precipitate and settle out the proteins and fibers. The supernatant is separated by decantation and concentrated to about half of its volume. The resulting concentrate is mixed with ethanol in the ratio of $1: 1$ to precipitate seed polysaccharide. Further purification of TG can be done by washing with ethanol and acetone. The tamarind gum so obtained is dried at $50^{\circ} \mathrm{C}$ for $24 \mathrm{~h}$, powdered and stored in container ${ }^{[22,45]}$.

\section{CHEMICAL MODIFICATION OF TG}

Despite being well suited for pharmaceutical application, TG exhibits some potential drawbacks. TG has a dull color and unpleasant odor. Its insolubility in water and degradation in an aqueous environment has forced the scientists to chemically modify its functional groups ${ }^{[46]}$ Various modifications which have been executed till date include carboxymethylation ${ }^{[47]}$, acetylation ${ }^{[48]}$, hydroxylalkylation $^{[49]}$ and thiolisation ${ }^{[50,51]}$. Such modifications have caused alteration in the solubility, viscosity, swelling and stability of TG.

\subsection{Carboxymethylation of $T G$}

Carboxymethyl tamarind gum (CMTG) is the derivative of TG containing carboxymethyl $\left(\mathrm{CH}_{2}-\mathrm{COOH}\right)$ groups. It is anionic in nature and used as a sodium salt. Chemically, its structure is similar to TG with addition of carboxymethyl group at $\mathrm{C} 6$ position which gives anionic nature to the polymer. Structure of CMTG is given in (Figure 2). Molecular weight of CMTG is approximately $\sim 9.14 \times 10^{5}$ $\mathrm{g} / \mathrm{mol}$ with intrinsic viscosity $9.0 \mathrm{dL} / \mathrm{g}$, which is higher than $\mathrm{TG}^{[52]}$. Molecular weight and viscosity of CMTG may vary with the degree of substitution of carboxymethyl group. Addition of carboxymethyl group increases the hydrophilicity of $\mathrm{TG}$ and resists its biodegradation ${ }^{[47]}$ CMTG is soluble in cold water ${ }^{[53]}$.

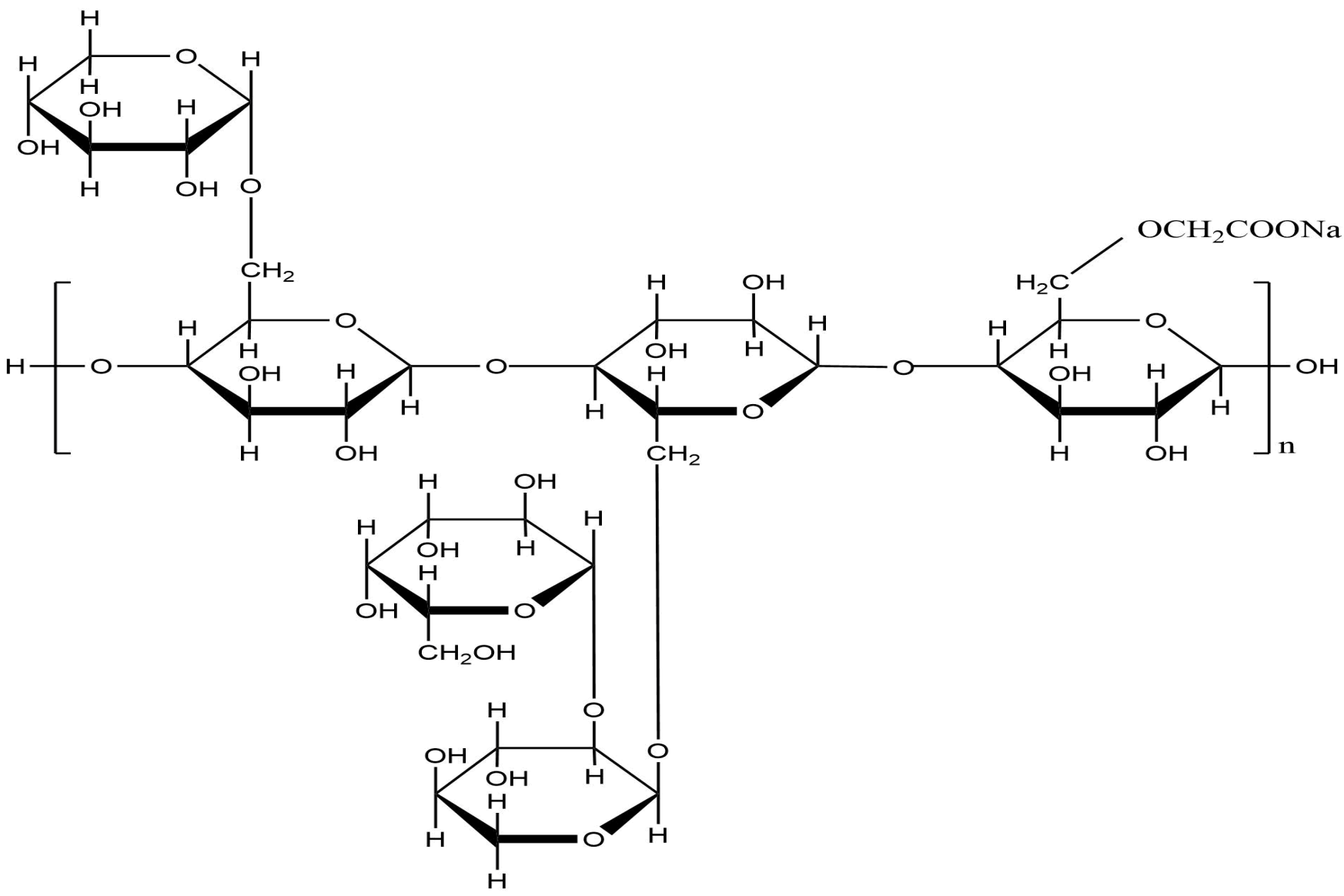

Fig. 2: Structure of carboxymethyl TG[54].

Carboxymethylation of $\mathrm{TG}$ can be done with monochloroacetic acid in the presence of sodium hydroxide as a catalyst. Scheme of carboxymethylation of TG is given in (Figure 3). Carboxymethylation of TG improves properties of native TG like unpleasant odor, dull color, water solubility, swelling, viscosity, bioadhesion, and biodegradability, thus making it appropriate for pharmaceutical applications ${ }^{[53]}$. 


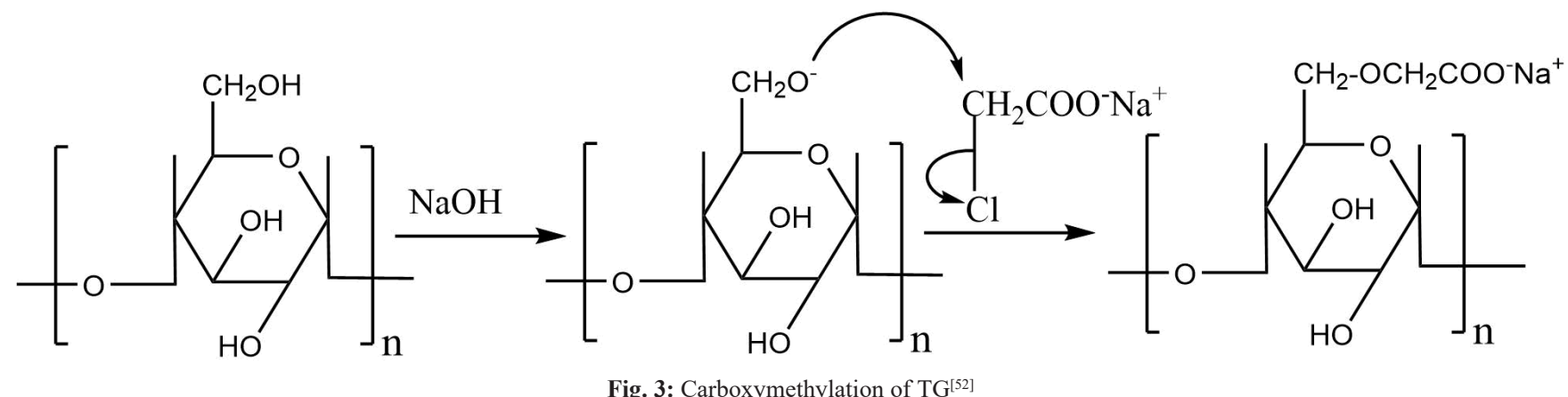

The swelling property of CMTG matrix tablets was studied by using gravimetric method in purified water. CMTG showed greater swelling than TG. The results indicate that an increase in degree of substitution (DS) of CMTG also increases its swellability. The enhancement in the swelling profiles may be due to carboxymethylation. The carboxymethylation of polymer increases the hydrophilicity which improves polymer wetting as well as swelling ${ }^{[55]}$. CMTG shows $\mathrm{pH}$ dependent swelling. In acidic environment, it has limited swelling while in basic environment it shows high swelling. Being an anionic polysaccharide, the carboxylic acid group of CMTG undergoes protonation at acidic $\mathrm{pH}$ which minimizes the repulsive forces between negatively charged carboxylate ions. As a result, the swellability of CMTG is reduced. This property of CMTG is desirable to avoid the release of acid labile drugs in gastric environment ${ }^{[52]}$. On the contrary, the basic environment causes deprotonation of carboxylic acid which causes electrostatic repulsion in between the negatively charged carboxylate ions. As a result, the network structure of the polymer may expand and absorb large amount of medium due to increase in its swellability. Such $\mathrm{pH}$ dependent swelling of CMTG could be beneficial for oral site specific drug delivery systems.

CMTG shows higher bioadhesion than TG which can be attributed to the highly hydrophilic nature of the polymer. CMTG contains hydroxyl and carboxyl groups which can form non-covalent bonds with biological tissue, resulting in bioadhesion ${ }^{[50]}$.

\subsection{Cynoethylation of TG}

Cynoethylation of TG is performed with acrylonitrile in presence of sodium hydroxide. Cynoethylation improves the properties like cold water solubility, viscosity, and biodegradation of TG. It is used in non-food applications ${ }^{[56]}$.

\subsection{Acetylation of TG}

Acetylation of TG can be done with glacial acetic acid and anhydrous sodium acetate. The acetyl derivative of TG is hydrophobic in nature ${ }^{[48]}$.

\subsection{Amination of $T G$}

An amine derivative of TG is prepared using ethylene diamine in presence of sodium borohydride as a reducing agent (see Figure 4). It is cationic in nature ${ }^{[57]}$. Amination of TG improves properties like hydrophilicity, swelling, and mucoadhesion of TG. Aminated TG forms strong gel in water which can be attributed to the complexation reaction between $\mathrm{NH}_{2}$ groups and water molecules to form $\mathrm{NH}_{3}{ }^{+}-\mathrm{OH}^{-}$. This interaction aids in the retention of the water molecules inside the matrix of aminated xyloglucan. Also, aminated TG exhibits antimicrobial activity ${ }^{[58]}$. Aminated TG shows higher bioadhesion than the sulfated and carboxymethylated $\mathrm{TG}^{[50]}$. It has been used in the development of buccoadhesive patch of pentazocine ${ }^{[59]}$. 


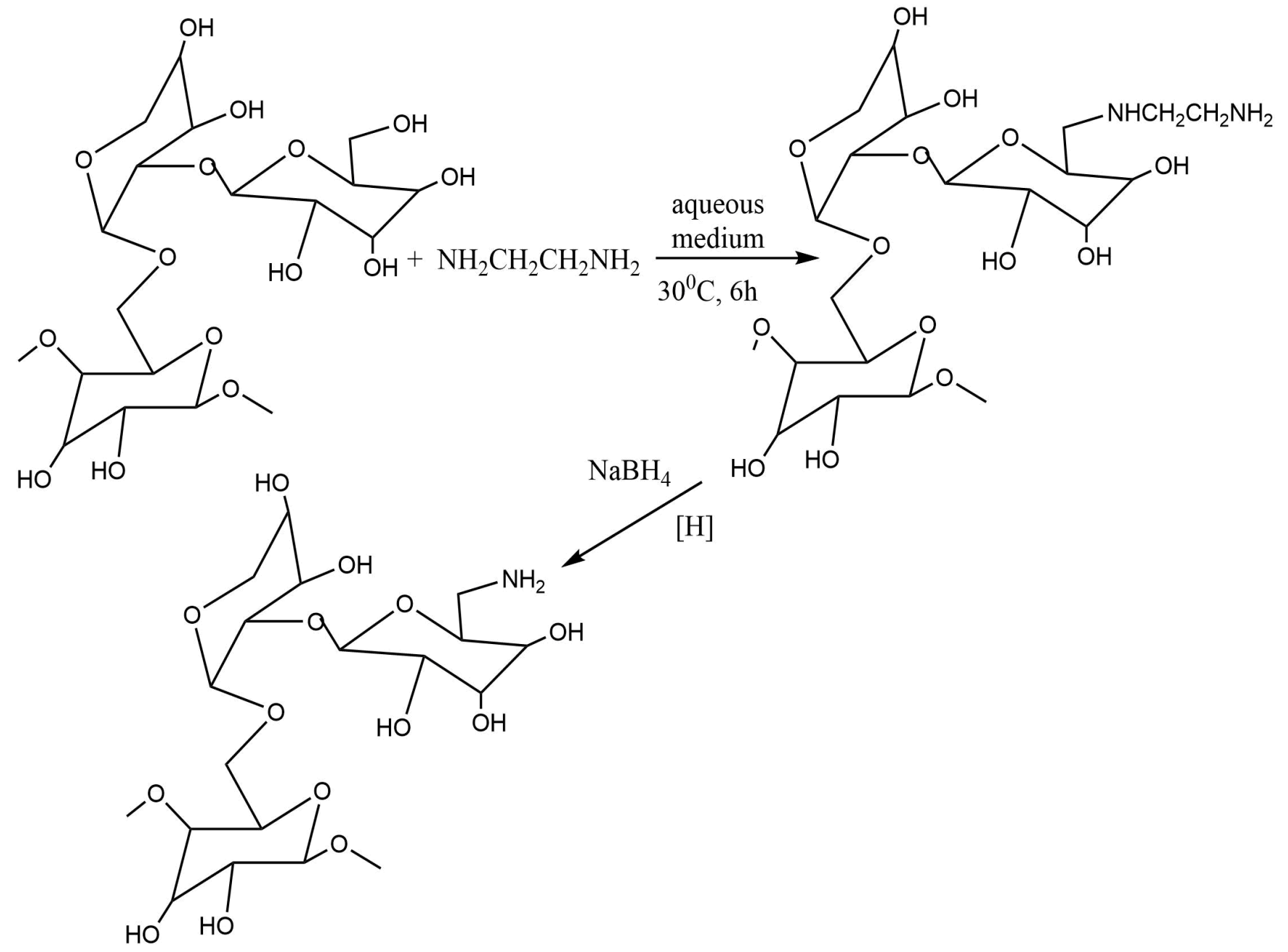

Fig. 4: Synthesis of aminated $\mathrm{TG}^{[50]}$

\subsection{Sulfonation of TG}

A sulfated derivative of TG is prepared using sulfur trioxide-pyridine complex in presence of DMF and sodium hydrogen carbonate (Figure 5). Sulfated TG may be used as release retardant in bioadhesive drug delivery ${ }^{[50,51]}$.<smiles>COC1C(O)C(O)C(O)C(O)C1COC1OCC(O)C(O)C1OC1OC(CO)C(O)C(O)C1O</smiles>

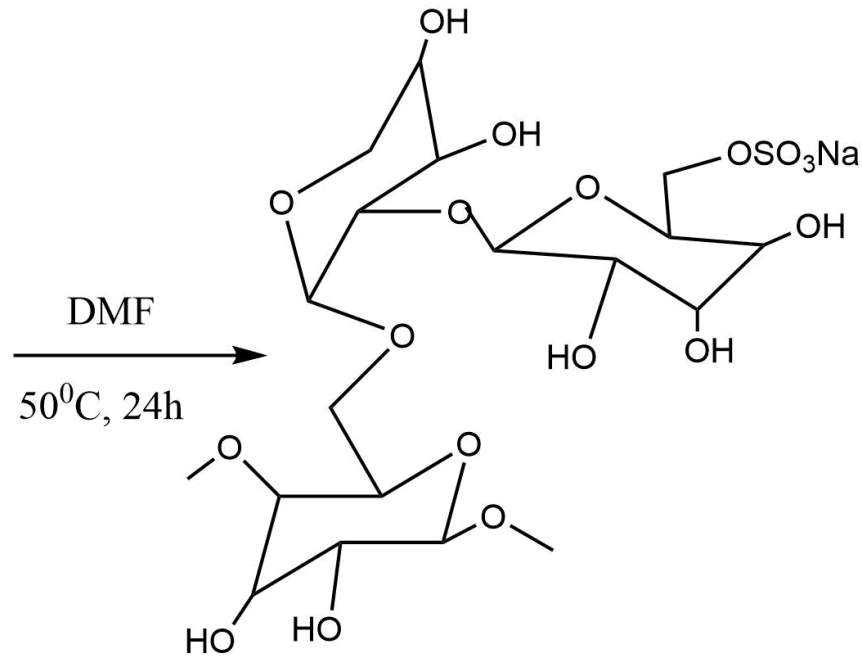

Fig. 5: Synthesis of sulfated $\mathrm{TG}^{[50]}$ 


\subsection{Thiolation of $T G$}

The thiolated TG is synthesized by using thioglycolic acid in presence of hydrochloric acid (Figure 6). The thiolated derivative is white in color and water soluble with higher mucoadhesion than native TG. It was used in mucoadhesive topical delivery of metronidazole ${ }^{[60]}$, and oral delivery of acyclovir ${ }^{[61]}$ and lopinavir ${ }^{[62]}$.
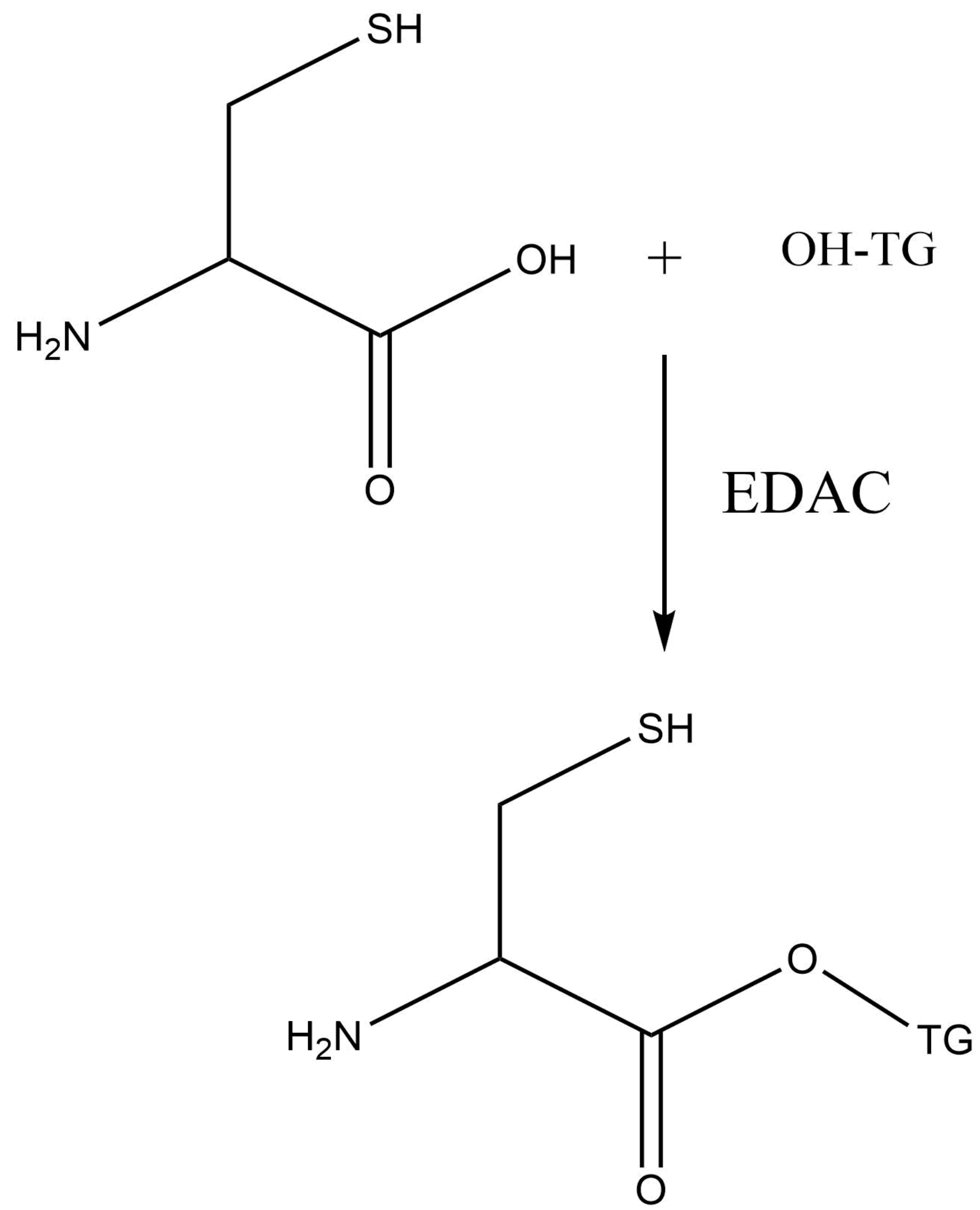

Fig. 6: Scheme for thioated $\mathrm{TG}^{[63]}$ 


\subsection{Crosslinking of TG}

Crosslinked TG can be used as a release retardant or matrix former in sustained or controlled drug delivery. Epichlorohydrin is used for the crosslinking of TG. It is used as a release retardant and matrix former for oral delivery of drugs ${ }^{[45]}$. Crosslinked TG has been used to develop matrix tablets of diclofenac ${ }^{[64]}$ and ketoprofen ${ }^{[64]}$, and mucoadhesive buccal patch of metronidazole ${ }^{[65]}$.

\subsection{Partially degraded TG}

Partially degraded TG is obtained by removing galactose residue from TG using beta-galactosidase enzyme. It shows thermoreversible gelation similar to Poloxamer 407 which makes it a suitable excipient in development of thermoreversible formulations for ophthalmic, oral, nasal and rectal delivery of drugs ${ }^{[66]}$. It has been used to prepare sustained release vehicle for delivery of ibuprofen and ketoprofen $^{[67]}$, oral sustained delivery of paracetamo[ ${ }^{[68]}$ and cimetidine ${ }^{[69]}$, nasal delivery of ondensetron ${ }^{[70]}$, rectal delivery of indomethacin and diltiazem ${ }^{[71]}$, and ocular delivery of pilocarpine ${ }^{[72]}$.

\subsection{Oxidized TG}

Oxidation of tamarind gum is carried out in aqueous solution by using periodate as oxidizing agent (see Figure 7). It is used in combination with chitosan to form hydrogels which has application in food and cosmetics $^{[73]}$<smiles>COC1C(O)C(O)C(O)C1COC1OCC(O)C(O)C1OC1OC(CO)C(O)C(O)C1O</smiles>

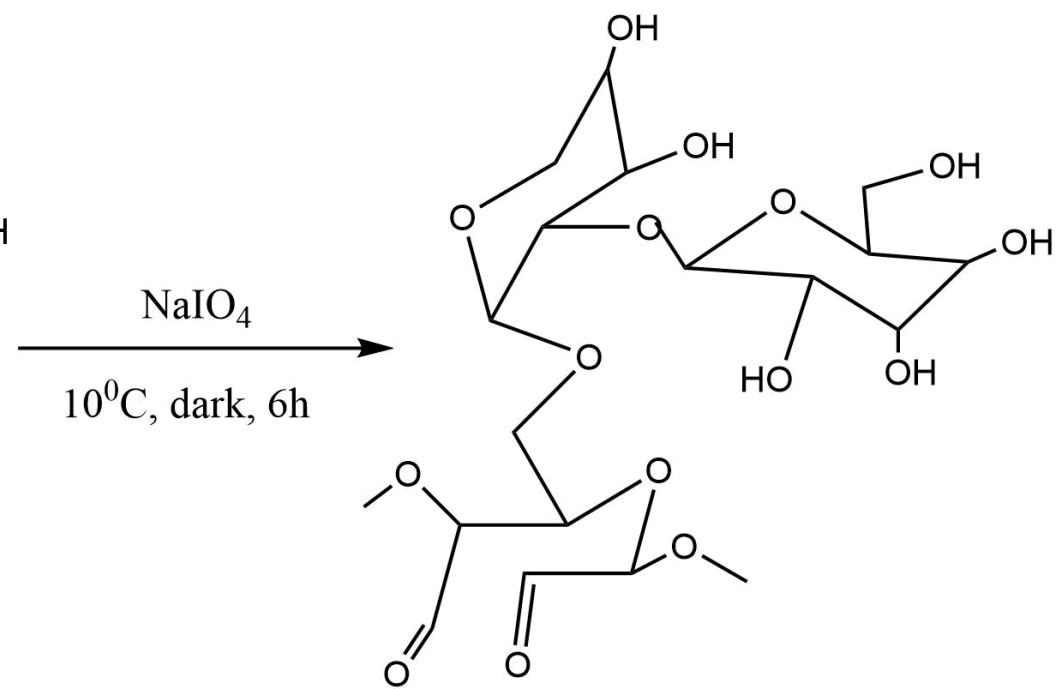

Fig. 7: Synthesis of oxidized $\mathrm{TG}^{[73]}$

\subsection{Graft-modified TG}

Grafting of TG with polyacrylamide and poly (N-vinyl-2-pyrrolidone) improves properties like matrix forming ability and mucoadhesion respectively ${ }^{[74,75]}$. Ahuja and Verma, (2014) attempted microwave-assisted synthesis of graft copolymer of carboxymethyl tamarind seed polysaccharide and polyacrylonitrile ${ }^{[76]}$. The results of swelling study revealed higher swelling of the graft copolymer in acidic and alkaline $\mathrm{pH}$ whereas lesser swelling at $\mathrm{pH}$ approaching to neutral. It indicates usefulness of graft co-polymer of TG in designing the $\mathrm{pH}-$ responsive applications.

\section{PHARMACEUTICAL APPLICATIONS OF TG} AND MODIFIED TG

\subsection{Liquid orals}

TG acts as a suspending agent by reducing the settling of particles and promoting the redispersion of settled particles. Paracetamol suspension has been prepared successfully using TG as a suspending agent. It also forms a stable emulsion at very low concentration ${ }^{[19,33]}$.

Partially degraded TG has been evaluated as sustained release vehicle for oral administration of indomethcin and diltiazem. The drug loaded aqueous solution was converted into gel in stomach after oral administration and showed Higuchi release kinetics. A threefold increment in the bioavailability of indomethacin was observed as compared to the suspension. The results of this study suggest the potential of the enzyme-degraded TG gels as vehicles for oral sustained delivery of drugs ${ }^{[77]}$. Similarly, cimetidine formulations were prepared with partially degraded TG. After oral administration of cimetidine to rabbits, the results of bioavailability were found to be close to the commercial formulation ${ }^{[69]}$. In another study, theophylline was investigated for oral sustained delivery in rabbits. The partially degraded TG helped to improve the bioavailability of theophylline by $1.7-2.5$ folds as compared to the commercial oral sustained-release liquid dosage forms ${ }^{[78]}$. Investigated liquid orals dosage form is listed in (Table 2). 
Table 2: Investigated liquid orals based on TG and modified TG

\begin{tabular}{lcccc}
\hline \multicolumn{1}{c}{ Therapeutic agent } & Formulation Type & Technique used & Excipients used & Role of Polymer \\
\hline Paracetamol $^{[79]}$ & Suspension & Trituration & TG & Suspending agent \\
Nimesulide $^{[80]}$ & Suspension & Trituration & TG & Suspending agent \\
NS $^{[28]}$ & Emulsion & Wet gum method & TG-castor oil & Emulsifying agent \\
Indomethacin, Diltiazem $^{[77]}$ & Liquid-In situ gel & Homogenization & Partially degraded TG & Vehicle for sustained release \\
Cimetidine $^{[69]}$ & Liquid-In situ gel & Homogenization & Partially degraded TG & Vehicle for sustained release \\
Theophylline $^{[78]}$ & Liquid-In situ gel & Homogenization & Partially degraded TG & Vehicle for sustained release \\
\hline
\end{tabular}

TG-tamarind gum; NS- Not specified; NA- Not applicable

\subsection{Oral drug delivery}

\subsubsection{Binder and matrix former in tablets}

The applicability of TG and modified TG in tablet dosage forms is summarized in (Table 3). TG and modified TG are used as dry binder as well as wet binder (aqueous and non aqueous) to prepare tablets. TG and CMTG have been used as dry binder for development of diclofenac ${ }^{[81]}$. TG has been used as a binder for wet granulation and suitable polymer for sustained release of terbutaline sulphate ${ }^{[82]}$ and diclofenac sodium ${ }^{[83]}$. TG and epichlorohydrin crosslinked TG has been investigated for the preparation of sustain release salicylic acid tablets. Crosslinked TG showed propensity to control the release of salicylic acid for extended period of time ${ }^{[84]}$. The ability of CMTG to improve the hardness of the tablet is reported by Huanbutta et al., 2016. They found that disintegration time of diclofenac sodium tablets containing CMTG was more than $\mathrm{TG}^{[85]}$. Matrix tablets of aceclofenac prepared by non aqueous wet granulation, using PVP as binder and TG as release retardant, showed sustained release for period of $12 \mathrm{~h}$ with anomalous release mechanism ${ }^{[86]}$. Due to the unique properties of TG like hydrophilicity, viscosity and high swelling, it has been used for formation of matrix tablets to achieve controlled release of drugs. TG forms hydrophilic matrix from which drug gets released in sustained or controlled manner for 8 to $24 \mathrm{~h}$. The retardation of drug release from the matrix depends on the physicochemical properties of the drug. It has been used in the development of gastroretentive drug delivery due to its mucoadhesive property. It has also been combined with other polymers like hydropropylmethylcellulose (HPMC) for preparation of matrix tablets ${ }^{[25]}$. TG has played an important role in the development of novel formulations like spheroids, microbeads, mucoadhesive microparticles, interpenetrating polymer networks (IPNs), microparticles and floating beads ${ }^{[19,21]}$.

TG has been explored as matrix former for preparation of sustained release tablet of verapamil HCl. Tablets prepared with TG showed high drug holding capacity. The in vitro release pattern of TG matrix was compared with the matrix of other polymers such as ethyl cellulose (EC), hydroxyethylcellulose (HEC) and HPMC, as well as commercial sustain release tablet. The results indicated a good correlation between in vitro and in vivo studies ${ }^{[25]}$. TG has been studied for controlled release behavior of water soluble and water insoluble drugs. Water soluble drugs showed anomalous release while water insoluble drugs showed near case II or zero order release behavior. It indicates that the release was controlled, by diffusion and erosion mechanism. The diluents like lactose and microcrystalline cellulose (MCC) prominently affected the release kinetics of water soluble and water insoluble drugs $^{[45]}$. The drug loading has negative effect on drug release from TG tablets. Compaction pressure and amount of lubricant up to $2 \%$ has no significant effect on the rate of drug release from TG tablets ${ }^{[87]}$.

TG has been used in combination with HPMC, PVP, cellulose acetate phthalate (CAP) and ethyl cellulose (EC) for development of matrix tablets of naproxen ${ }^{[88]}$ and metformin ${ }^{[89]}$. The addition of HPMC in formulation increased the swelling while CAP and EC decreased swelling of the tablets. The prepared tablet showed ability to retard naproxen release over a period of $8 \mathrm{~h}^{[88]}$. The floating tablet of metformin was optimized by Rajab et al (2014), using different polymer ratios of PVP, TG, and HPMC. They concluded that the difference in the in vitro performance of tablets is due to the differences in the hydrophilic properties of the polymers and the ability of PVP to interact with HPMC or $\mathrm{TG}^{[89]}$. This indicates that TG exhibits good release retardant property when used alone or in combination with other hydrophilic polymers.

TKP, acrylic acid, and polyamidoamine were used for the synthesis of $\mathrm{pH}$-responsive polymer, intended for oral controlled release of 5-aminosalicylic acid. The swelling study indicated $\mathrm{pH}$-responsive nature of the synthesized polymer. The in vitro release profiles of drug showed sustained release behavior over a period of time, indicating that the polymeric material could find potential applications for controlled oral delivery of various therapeutic agents ${ }^{[90]}$.

Due to the upper hand of CMTG over TG, it is widely accepted by the researchers for the preparation of various controlled release systems. CMTG shows low swelling at acidic $\mathrm{pH}$ and is highly desirable for its application as drug delivery matrix in the harsh environment of the stomach. The matrix of CMTG remained intact for $24 \mathrm{~h}$ and showed ability to release the drug at higher $\mathrm{pH}$. From the CMTG matrix, drug is released by non-Fickian release mechanism ${ }^{[52]}$. To control burst release from CMTG matrix, CMTG is used in combination with HPMC for delivery of tramadol. The combination of CMTG and HPMC showed good matrix integrity and showed regulated and complete release of tramadol at the end of $10 \mathrm{~h}$ with anomalous release 
mechanism. The results revealed that the HPMC can prevent the initial burst release of drug while CMTG can sustain the drug release at later stage of release profile. The study indicated that appropriate balance between concentration of polymers could give better results ${ }^{[91]}$. The mucoadhesive gastroretentive tablet of metformin has been prepared using CMTG. The results indicated that replacement of fraction of CMTG with HPMC in formulation can help to adjust swelling and metformin release while adhesion of swollen tablets remained unchanged ${ }^{[92]}$. Hence, CMTG can be used as a matrix former, release retardant and mucoadhevise agent in the development of oral sustained or controlled drug delivery system.

Further, thiolated CMTG has been used for the gastroretentive delivery of simvastatin, due to its high mucoadhesive nature. Initially, TG is chemically modified to CMTG and converted to thiomer by conjugation with cysteine. The tablets prepared using CMTG thiomer showed linear drug release retardation with increasing amount of thiomer over a period of $8 \mathrm{~h}$. Tablets containing highest thiomer concentration showed more drug permeation and highest mucoadhesive strength ${ }^{[93]}$.

Table 3: Investigated TG and modified TG as binder and release retardant

\begin{tabular}{|c|c|c|c|c|c|}
\hline Therapeutic agent & Formulation type & Technique used & Excipients used & Role of Polymer & Animals used \\
\hline Diclofenac sodium $^{[81]}$ & Tablet & Direct compression & TG, CMTG & Binder & NA \\
\hline Diclofenac sodium $^{[85]}$ & Tablet & Dry granulation & TG, CMTG & Binder & NA \\
\hline Terbutaline sulphate ${ }^{[82]}$ & Tablet & Wet granulation & TG & Binder, release retardant & NA \\
\hline Diclofenac sodium $^{[83]}$ & Tablet & Wet granulation & TG & Release retardant & NA \\
\hline Salicylic acid ${ }^{[84]}$ & Tablet & Direct compression & TG-epichlorohydrin & Release retardant & NA \\
\hline Aceclofenac $^{[86]}$ & Tablet & Wet granulation & TG & Release retardant & NA \\
\hline Verapamil $\mathrm{HCl}^{[25]}$ & Tablet & Direct compression & TG & Release retardant & Rabbits \\
\hline Tramadol $^{[94]}$ & Multilayer Tablet & $\begin{array}{l}\text { Wet granulation } \\
\text { followed by } \\
\text { compression }\end{array}$ & TG & $\begin{array}{l}\text { Release retardant, } \\
\text { matrix former }\end{array}$ & NA \\
\hline $\begin{array}{l}\text { Salicylic acid, } \\
\text { indomethacin, } \\
\text { theophylline }{ }^{[45]}\end{array}$ & Tablet & Direct compression & TG, TG-epichlorohydrin & Release retardant & NA \\
\hline Caffeine $^{[87]}$ & Tablet & Direct compression & TG & Release retardant & NA \\
\hline Naproxen $^{[88]}$ & Tablet & Wet granulation & TG-HPMC, TG-CAP, TG-EC & Matrix former & NA \\
\hline Metformin $^{[89]}$ & Tablet & Wet granulation & TG-PVP-HPMC & Mucoadhesion & NA \\
\hline 5-aminosalicylic acid ${ }^{[90]}$ & Film & $\begin{array}{l}\text { Crosslinking followed } \\
\text { by freeze drying }\end{array}$ & $\begin{array}{l}\text { TG-acrylic acid- } \\
\text { polyamidoamine }\end{array}$ & $\mathrm{pH}$ dependent release & NA \\
\hline Tramadol $^{[91]}$ & Tablet & Wet granulation & CMTG-HPMC & Release retardant & NA \\
\hline Simvastatin $^{[93]}$ & Tablet & Direct compression & Thiolated CMTG & Mucoadhesive & NA \\
\hline Famotidine $^{[95]}$ & Tablet & $\begin{array}{l}\text { Wet granulation } \\
\text { followed by } \\
\text { compression }\end{array}$ & TG-Xanthan Gum & Matrix former & NA \\
\hline Verapamil $\mathrm{HCl}^{[96]}$ & Tablet & $\begin{array}{l}\text { Non aqueous wet } \\
\text { granulation }\end{array}$ & HPMC-CMTG & Bioadhesive & NA \\
\hline
\end{tabular}

TG-tamarind gum; CMTG- carboxymethyl tamarind gum; HPMC- hydropropylmethyl cellulose; XG- xanthan gum; NA- not applicable

\subsubsection{Interpenetrating networks}

Interpenetrating networks (IPNs) is the novel approach used for oral delivery of drugs. The delivery of drug from the TG based matrices can also be controlled by generating IPN structures between TG and suitable polymer within the matrix (see Table 4). Aceclofenac loaded IPN microparticles of chitosan and TG blend has been prepared using glutaraldehyde as a crosslinking agent. IPNs showed sustained release of aceclofenac over a period of $8 \mathrm{~h}$. The in vivo studies in carrageenan induced rat-paw oedema model indicated sustained action of aceclofenac loaded IPNs ${ }^{[97]}$. The matrix tablets of aceclofenac loaded IPNs showed sustained release over $8 \mathrm{~h}$ with anomalous diffusion release mechanism. These matrix tablets might be helpful to minimize dosing frequency and reduction of various side effects of aceclofenac during prolong period of treatment ${ }^{[98]}$. TG- sodium alginate (SA) IPNs have been prepared by wet granulation/covalent cross-linking method and ionotropic gelation, for controlled release of propranolol ${ }^{[99]}$ and diltiazem ${ }^{[100]}$ respectively. The IPN matrices showed drug release up to $24 \mathrm{~h}$ with non-Fickian release mechanism. The oral IPN beads of diltiazem exhibited comparatively higher AUC values than the pure drug in rats. It can be inferred that IPNs of TG-SA would be useful matrices for water-soluble drugs.

CMTG has also attracted the scientists dealing with the IPNs based drug delivery. IPNs containing acyclovir has been prepared using CMTG and SA by ionotropic gelation method. The IPNs are spherical in shape with rough surface texture. The CMTG and SA in weight ratio of 3:1 showed maximum drug entrapment. The in vitro release data revealed that less than $23 \%$ of acyclovir was released 
in acidic medium ( $\mathrm{pH}$ 1.2) followed by faster release of drug in phosphate buffer ( $\mathrm{pH}$ 6.8). The drug release was controlled by diffusion and swelling kinetics of IPNs with non-Fickian drug release behavior ${ }^{[101]}$. The aceclofenac loaded glutaraldehyde crosslinked IPNs has been prepared by using gelatin and CMTG as a polymer. The addition of CMTG in formulation improved the drug entrapment efficiency of the IPNs. The prepared IPNs retarded drug

Table 4: Investigated TG and modified TG based IPNs

\begin{tabular}{|c|c|c|c|c|c|}
\hline Therapeutic agent & Formulation type & Technique used & Excipients used & Role of Polymer & Animals used \\
\hline Aceclofenac ${ }^{[97,98]}$ & IPNs, (Tablet) & $\begin{array}{cl}\text { covalent cross } & \begin{array}{l}\text { linking followed by direct } \\
\text { compression }\end{array}\end{array}$ & TG-CH (GA) & Release controlling agent & Rat \\
\hline Propranolol ${ }^{[99]}$ & IPNs, (Tablet) & Wet granulation/covalent cross linking & TG-SA (GA) & Release retardant & NA \\
\hline Diltiazem $^{[100]}$ & IPNs (beads) & Ionotropic gelation and covalent cross linking & $\mathrm{TG}-\mathrm{SA}\left(\mathrm{CaCl}_{2}\right.$ and $\left.\mathrm{GA}\right)$ & Release retardant & Rats \\
\hline Aceclofenac ${ }^{[102]}$ & IPNs & covalent cross linking followed by freeze-drying & CMTG-Gelatin (GA) & Release retardant & Rats \\
\hline Acyclovir ${ }^{[101]}$ & IPNs & Ionotropic gelation & CMTG-SA $\left(\mathrm{CaCl}_{2}\right)$ & Release controlling agent & NA \\
\hline Aceclofenac ${ }^{[103]}$ & IPNs & covalent cross linking & CMTG-CH & Release retardant & NA \\
\hline
\end{tabular}

TG-tamarind gum; SA-sodium alginate; CH-chitosan; GA-glutaraldehyde; CMTG-carboxymethyl tamarind gum; NA- not applicable

\subsubsection{Hydrogels}

Hydrogels are three dimensional crosslinked polymeric network structures which are highly porous and have tendency to absorb aqueous medium without getting dissolved in it. Due to the unique properties of hydrogels, they are widely used in drug delivery ${ }^{[104]}$. TG and modified TG have been used, alone or in combination with other polymers, by various researchers for the preparation of hydrogel-based drug delivery systems (see Table 5). Moxifloxacin loaded TG based hydrogels has been prepared by physical gelation method. TG was used in the concentration range of 10 to $25 \%$ w/w. Drug loaded TG solutions were heated on water bath at $70{ }^{\circ} \mathrm{C}$ for 5 minutes and stored at $5{ }^{\circ} \mathrm{C}$ for $2 \mathrm{~h}$. TG hydrogels were thermostable in nature and formed spreadable hydrogels. The prepared hydrogels have capacity to retard drug release for longer time in its active form and showed good antimicrobial activity ${ }^{[42]}$. Further, TG has been used release in $\mathrm{HCl}$ and extended it in phosphate buffer, $\mathrm{pH} 6.8$. The release of aceclofenac from IPNs was dependent upon the extent of crosslinking and concentration of CMTG. The in vitro drug release was controlled by polymer chain relaxation/swelling and simple diffusion. Aceclofenac loaded IPNs showed anti-inflammatory activity for $7 \mathrm{~h}$ in albino rats. The results suggest potential application of IPNs of gelatin-CMTG in oral controlled drug delivery ${ }^{[102]}$.

Table 5: Investigated TG and modified TG based hydrogels

\begin{tabular}{|c|c|c|c|c|c|}
\hline Therapeutic agent & Formulation type & Technique used & Excipients used & Role of Polymer & Animals used \\
\hline Moxifloxacin $^{[42]}$ & Hydrogel & Physical gelation & TG & Matrix former & NA \\
\hline Vancomycin $^{[105]}$ & Hydrogel film & Chemical crosslinking & TG-CMC (CA) & Matrix former & mice \\
\hline Moxifloxacin $^{[107]}$ & Hydrogel film & Chemical crosslinking & TG-CMC (CA) & Matrix former & NA \\
\hline Ciprofloxacin $^{[106]}$ & Phase separated hydrogels & $\begin{array}{c}\text { Solution casting, } \\
\text { Covalent crosslinking }\end{array}$ & TG-gelatin CMTG-gelatin (GA) & $\begin{array}{l}\text { Mucoadhesive, Vehicle } \\
\text { for enteric drug delivery }\end{array}$ & NA \\
\hline Metronidazole ${ }^{[108]}$ & Cryogel & Physical crosslinking & CMTG-PVA & Release controlling agent & NA \\
\hline Moxifloxacin $^{[54]}$ & Hydrogel film & Chemical crosslinking & CMTG & Matrix former & NA \\
\hline Aspirin $^{[74]}$ & Hydrogel tablet & $\begin{array}{c}\text { Microwave assisted } \\
\text { grafting, Wet granulation }\end{array}$ & TKP-g-PAM & $\begin{array}{c}\text { Matrix for } \mathrm{pH} \text { dependent } \\
\text { release }\end{array}$ & NA \\
\hline $\mathrm{NS}^{[109]}$ & Hydrogel & Grafting & CMTG-HEMA & $\begin{array}{c}\text { Matrix for Bone tissue } \\
\text { engineering }\end{array}$ & NA \\
\hline $\mathrm{NS}^{[110]}$ & Hydrogel & copolymerization & CMTG-g-Polyacrylonitrile & adsorbant & NA \\
\hline
\end{tabular}

TG-tamarind gum; CA- citric acid; CMTG-carboxymethyl tamarind gum; CMC- carboxymethylcellulose; GA-glutaraldehyde; PVA-polyvinyl alcohol; NAnot applicable; NS- not specified 
The metronidazole loaded composite hydrogels of CMTG and polyvinyl alcohol has been prepared by freeze thaw-treatment. The higher concentration of CMTG increases drug release while higher levels of PVA in cryogels favors sustained release of drug. The optimized cryogel showed maximum swelling up to $600 \%$, lesser degree of crystallinity and enhanced thermal stability than the individual polymers. The prepared cryogels released $75 \%$ of metronidazole over period of $6 \mathrm{~h}$ following the Higuchi release kinetics. The result suggests potential application of CMTG-PVA cryogels in drug delivery ${ }^{[108]}$. Hydrogel has also been prepared by grafting hydroxyethyl methacrylate (HEMA) on CMTG. The prepared hydrogel material was suitable for effective adhesion, growth and further clustering of bone precursor cells. The hydrogel was compatible for growing cells. Hydrogel made of CMTG:HEMA at a ratio of 1:10 can be suitable for bone tissue engineering and thus may have clinical as well as commercial application in the future ${ }^{[109]}$.

\subsubsection{Spheroids and pellets}

Besides tablet dosage form, TG and CMTG have also been used for the preparation of drug loaded spheroids and pellets (see Table 6). The spheroids of diclofenac have been prepared using TG as release modifier and $\mathrm{MCC}$ as filler. Extrusion spheronization technique has been used for the preparation of spheroids. The in vitro release studies exhibited zero-order release kinetics. The bioavailability study indicated that the developed spheroids have ability to sustain the drug release over $8 \mathrm{~h}$ and could improve the extent of absorption and bioavailability of the drug ${ }^{[111]}$. Sustained release tablet of lornoxicam has been prepared by extrusion/spheronisation using CMTG and MCC. The prepared spheroids showed good flow properties due to their spherical shape. The formulation with $10 \% \mathrm{w} / \mathrm{w}$ CMTG sustained the release of lornoxicam over a period of $12 \mathrm{~h}$. The results suggest the potential use of CMTG and MCC blends for the development of controlled drug delivery systems ${ }^{[112]}$. Also, CMTG has been used for the development of lansoprazole ${ }^{[13]}$ and curcumin ${ }^{[114]}$ pellets using extrusion-spheronization technique. MCC was used as filler in combination with CMTG for preparation of pellets. Solid dispersion pellet prepared with CMTG showed two fold increase in the oral bioavailability of curcumin in rats than the pellet of pure drug. These studies indicate the industrial suitability of CMTG in development of pharmaceutical formulations by extrusionspheronization technique.

Table 6: Investigated TG and modified TG based spheroids and pellets

\begin{tabular}{lcccc}
\hline Therapeutic agent & Formulation type & Technique used & Excipients used & \multicolumn{2}{c}{ Role of Polymer } & Animals used \\
\hline Diclofenac $^{[111]}$ & Spheroids & Extrusion spheronization & TG-MCC & Release retardant \\
Lornoxicam[112] $^{113]}$ & Pellets & Extrusion spheronization & CMTG-MCC & Release retardant \\
Lansoprazole $^{[113]}$ & Pellets & Extrusion spheronization & CMTG-MCC & Release retardant \\
Curcumin $^{[14]}$ & Pellets & Extrusion spheronization & CMTG-MCC & Carrier \\
Ibuprofen $^{[115]}$ & Pellets & Extrusion spheronization & CMTG-MCC & Rats \\
\hline
\end{tabular}

TG-tamarind gum; MCC-microcrystalline cellulose; NA- not applicable

\subsubsection{Microbeads}

Table 7 summarizes the application of $\mathrm{TG}$ and CMTG in microbead formulations. TG is used for the development of $\mathrm{pH}$-sensitive microbeads in combination with $\mathrm{SA}^{[116]}$, gellan gum ${ }^{[117]}$ and pectin ${ }^{[118]}$. $\mathrm{pH}$-sensitive composite beads of $\mathrm{TG}$ and sodium alginate/ gellan gum for controlled release of diclofenac sodium ${ }^{[119]}$ and metformin $^{[116]}$ have been prepared by ionotropic gelation method using calcium chloride as a crosslinking agent. TG-polymer beads showed high drug encapsulation and good mucoadhesivity. Microbeads showed $\mathrm{pH}$ dependent swelling with minimum swellability in $0.1 \mathrm{~N} \mathrm{HCl}$ and high swellability in phosphate buffer of $\mathrm{pH} 6.8$ or 7.4. Microbeads showed tendency to control the drug release for prolonged period. From microbeads, drug is released by swelling and relaxation of the matrix ${ }^{[119]}$. The in vivo studies of Metformin loaded mucoadhesive microbeads showed prolonged $(10 \mathrm{~h})$ anti-diabetic effect in alloxan induced diabetic rats due to retention of microbeads in stomach $^{[116-118]}$. Further, TG is utilized in development of floating microbeads. Alginate gel-coated oil-entrapped calcium alginate-TG-magnesium stearate composite floating beads have been used for intragastric risperidone delivery. The beads exhibited superior buoyancy and sustained drug release property. The drug is released by the anomalous diffusion driven mechanism. The composite beads are suitable for intragastric delivery of risperidone over a prolonged period of time ${ }^{[120]}$. 
Table 7: Investigated TG and modified TG based microbeads

\begin{tabular}{|c|c|c|c|c|c|}
\hline Therapeutic agent & Formulation type & Technique used & Excipients used & Role of Polymer & Animals used \\
\hline Metformin $^{[116]}$ & beads & Ionotropic gelation method & TG-SA $\left(\mathrm{CaCl}_{2}\right)$ & Mucoadhesive, & Rats \\
\hline Metformin $^{[117]}$ & beads & Ionotropic gelation method & TG-gellan $\left(\mathrm{CaCl}_{2}\right)$ & Mucoadhesive, & Rats \\
\hline Metformin $^{[118]}$ & beads & Ionotropic gelation method & TG-Pectin $\left(\mathrm{CaCl}_{2}\right)$ & Mucoadhesive, & NA \\
\hline Diaclofenac $^{[119]}$ & beads & Ionotropic gelation method & TG-SA $\left(\mathrm{CaCl}_{2}\right)$ & Matrix former & NA \\
\hline Risperidone $^{[120]}$ & Floating microbeads & Ionotropic emulsion gelation & TG-SA $\left(\mathrm{CaCl}_{2}\right)$ & Matrix former & NA \\
\hline Aceclofenac $^{[121]}$ & microbeads & $\begin{array}{l}\text { Free radical polymerization, Ionic } \\
\text { crosslinking }\end{array}$ & $\begin{array}{l}\text { Polyacrylamide-g-CMTG } \\
\text { (ferric ion) }\end{array}$ & $\mathrm{pH}$ responsive release & NA \\
\hline
\end{tabular}

TG-tamarind gum; SA-sodium alginate; CMTG-carboxymethyl tamarind gum; NA- not applicable

\subsubsection{Microspheres}

Very few reports are available on the applicability of TG and modified TG in the microparticle based drug delivery systems (see Table 8). TG has been used in combination with alginate for preparation of mucoadhesive microspheres for oral gliclazide delivery. Ionotropic gelation method was used for the preparation of microspheres. Calcium chloride was used as a crosslinker. The gliclazide loaded TG-alginate microspheres showed prolonged in vitro release over 12 hours at gastric and intestinal $\mathrm{pH}$ conditions. The release of gliclazide in gastric $\mathrm{pH}$ was comparatively slow and sustained than intestinal pH. TGSA microspheres exhibited good mucoadhesivity. After an oral administration of TG-alginate microspheres to the alloxan-induced diabetic rats, a significant hypoglycemic effect was observed ${ }^{[122]}$.

Glipizide loaded sodium trimetaphosphate crosslinked

Table 8: Investigated TG and modified TG based microspheres mucoadhesive microspheres were prepared using TG and thiolated TG by w/o emulsification method. Thiolated TG microspheres showed high entrapment efficiency and mucoadhesion than TG microspheres. Microspheres prepared with thiolated TG controlled drug release over a period of $8 \mathrm{~h}$ and showed better control of blood sugar in alloxan induced diabetic rats. Hence, thiolated TG offers a better polymer for multiparticulate drug delivery systems $^{[123]}$.

Mucoadhesive microspheres of lopinavir have been prepared using thiolated TG and SA by ionotropic gelation method. The in vitro release profile showed that the microspheres have ability to control release up to $6 \mathrm{~h}$ and follows case I type of release behavior. The study indicated improvement of lopinavir bioavailabilty in rats due to absorption enhancing effect of thiolated $\mathrm{TG}^{[62]}$.

\begin{tabular}{|c|c|c|c|c|c|}
\hline Therapeutic agent & Formulation type & Technique used & Excipients used & Role of Polymer & Animals used \\
\hline Gliclazide $^{[122]}$ & Oral microparticles & Ionotropic gelation & TG-SA $\left(\mathrm{CaCl}_{2}\right)$ & Mucoadhesive & Rats \\
\hline Glipizide $^{[123]}$ & Oral microparticles & w/o emulsification & Thiolated TG (STMP) & Permeation enhancer & Rats \\
\hline Lopinavir $^{[62]}$ & Oral microparticles & Ionotropic gelation method & Thiolated TG-SA $\left(\mathrm{CaCl}_{2}\right)$ & Mucoadhesive & Rats \\
\hline
\end{tabular}

TG-tamarind gum; STMP-sodium trimetaphosphate; NA- not applicable

\subsubsection{Nanoparticles}

In last few years, TG and modified TG have been used for the preparation of nanoparticles (see Table 9). Mucoadhesive nanoparticles of TG-SA were prepared for the oral sustained delivery of anticancer drug, irinotecan. The drug-loaded nanoparticles were prepared by iongelation method using calcium chloride as crosslinking agent. The in vitro drug release profile showed initial burst release followed by controlled release pattern, showing up to $60 \%$ drug release in $12 \mathrm{~h}$. TG may be suitable for formulation of mucoadhesive nanoparticles for better efficacy and sustained delivery of irinotecan with reduced toxicity ${ }^{[124]}$.

The ciprofloxacin loaded CMTG nanoparticles were synthesized by ionotropic gelation method using magnesium chloride as a crosslinker. The prepared nanoparticles were ovoid in shape. The concentration of CMTG and crosslinker had a positive effect on encapsulation efficiency. The antibacterial assay results revealed greatest zone of inhibition by ciprofloxacin- loaded CMTG nanoparticles in Micrococcus luteus. The results of cytotoxicity study indicated minimum toxic nature of ciprofloxacin-loaded CMTG nanoparticles ${ }^{[125]}$.

Besides, silver nanoparticles (AgNP) have been prepared by in situ reduction and capping with CMTG. The prepared nanoparticles exhibited average particle size of $\sim 20-40 \mathrm{~nm}$ and showed long time stability. These AgNPs inhibit the growth and biofilm formation of both Gram positive and Gram negative bacterial strains even at low concentration of antibiotics. CMTG-capped AgNPs have potential for bio-medical application against multi-drugresistant microbes, with minimal cytotoxicity towards mammalian cells ${ }^{[126]}$.

Aminated TG forms self-assembled spherical nanoparticles of $60 \mathrm{~nm}$ size at a very low concentration $(0.2 \%, \mathrm{w} / \mathrm{v})$ in an aqueous medium and forms strong hydrogel. The TG-NH2 shows better antimicrobial activity in comparison to chitosan. This modified TG has potential applications in the medical and biotronics field because it possesses biocompatibility and strong hydrogel behavior 
with very useful blue fluorescence ${ }^{[58]}$. Acyclovir loaded thiolated TG nanoparticles have been prepared using sodium trimetaphosphate as a crosslinker. The prepared acyclovir nanoparticles have showed high drug entrapment and mucoadhesion. The in vitro drug release behavior Table 9: Investigated TG and modified TG based nanoparticles indicated sustained release of acyclovir form nanoparticles over a period of $8 \mathrm{~h}$. The in vivo study in rats indicated improvement in bioavailability of acyclovir compared to the marketed formulation ${ }^{[61]}$.

\begin{tabular}{|c|c|c|c|c|c|}
\hline Therapeutic agent & Formulation type & Technique used & Excipients used & Role of Polymer & Animals used \\
\hline Irinotecan $^{[124]}$ & Oral nanoparticles & $\begin{array}{l}\text { Ionotropic gelation method, } \\
\text { homogenization followed by lyophilization }\end{array}$ & TG-SA $\left(\mathrm{CaCl}_{2}\right)$ & Mucoadhesive & NA \\
\hline Acyclovir $^{[61]}$ & Oral nanoparticles & Mechanical stirring followed by lyophilisation & Aminated TG (STMP) & Mucoadhesive & Rats \\
\hline Silver ${ }^{[126]}$ & nanoparticles & Situ reduction and capping & CMTG & Carrier & NA \\
\hline Ciprofloxacin ${ }^{[125]}$ & nanoparticles & $\begin{array}{c}\text { gelation method followed by } \\
\text { lyophilization }\end{array}$ & CMTG $\left(\mathrm{MgCl}_{2}\right)$ & Carrier & NA \\
\hline
\end{tabular}

TG-tamarind gum; CMTG-carboxymethyl tamarind gum; STMP- sodium trimetaphosphate; NA- not applicable

\subsubsection{Solid dispersion}

TG has also been explored to enhance solubility of aceclofenac, atorvastatin and irbesartan by solid dispersion technique. Satle and Agrawal (2012) suggested that the proper use of TG can enhance solubility of poorly soluble drugs $^{[127]}$. Further, effect of method of preparation of solid dispersion on dissolution rate of celecoxib has been studied using TG. Solid dispersions have been prepared using co-grinding method, kneading method and solvent deposition. Dissolution rate of drug was increased as the TG concentration increased and optimum weight ratio was found to be 1:4 (drug:TG). Among all the methods, though the solvent deposition technique improved the dissolution rate to maximum, co-grinding technique was found to be suitable from practical point of view and commercialization $^{[128]}$.

\subsection{Buccal drug delivery}

TG can be used in the formulation of buccal drug delivery systems like buccal tablets, buccal films, and buccal patches (see Table 10). TG shows buccoadhesive property and ability to control release over a period of $8 \mathrm{~h}$. TG has been used in buccal drug delivery of various drugs like rizatriptan benzoate ${ }^{[129]}$, nifedipine ${ }^{[130]}$, nitrendipine ${ }^{[131]}$, benzydamine $e^{[32]}$ lidocaine ${ }^{[23]}$ and metronidazole ${ }^{[19,21]}$. Simple compression method has been used to prepare mucoadhesive buccal patches of benzydamine and lidocaine. The patch is adhered for more than $8 \mathrm{~h}$ to buccal mucosa and showed controlled drug release ${ }^{[32]}$. The metronidazole loaded epichlorohydrin crosslinked mucoadhesive patches of TG have been prepared by solvent casting method for buccal delivery. Drug loaded patches showed adequate mucoadhesive strength. More than $70 \%$ of drug got diffused across the semipermeable membrane at low concentration of plasticizer and crosslinker. So, TG can be well utilized to develop buccal drug delivery system with optimum mucoadhesive strengt ${ }^{\mathrm{h}}[65]$. Buccal bioadhesive patches of pentazocine hydrochloride have been prepared by employing aminated and sulfated derivatives of TG. The in vitro release of the drug was found to be dependent on the swelling index of polymers. The sulfated TG patch released drug at a faster rate as compared to the aminated TG patches. The oral administration of aminated patches to rats was found to enhance the bioavailability of pentazocine hydrochloride 2.8 times as compared to the oral solution ${ }^{[59]}$.

Table 10: Investigated TG and modified TG based buccal drug delivery systems

\begin{tabular}{lcccc}
\hline \multicolumn{1}{c}{ Therapeutic agent } & Formulation type & Technique used & Excipients used & Role of Polymer \\
\hline Rizatriptan benzoate $^{[129]}$ & Buccal Film & Solvent casting & TG-Carbopol 934 & Animals used \\
Nifedipine $^{[130]}$ & Tablet & Direct compression & TG-Carbopol 934 & Mucoadhesive, Matrix former \\
Nitrendipine $^{[131]}$ & Tablet & Wet granulation & TG- Z. Mauritiana mucilage & Mucoadhesive, release retardant \\
Benzydamine, lidocaine $^{[32]}$ & Buccal patch & Direct compression & NG \\
Metronidazole $^{[65]}$ & Buccal patch & Solvent casting & TG-Epichlorohydrine & Mucoadhesive \\
Pentazocinehydrochloride $^{[59]}$ & Buccal Film & Solvent casting & Aminated TG & Mucoadhesive \\
\hline
\end{tabular}

TG-tamarind gum; NA- not applicable

\subsection{Ophthalmic drug delivery}

The high viscosity and mucoadhesive nature of TG make it a suitable excipient in development of ocular formulations (see Table 11). These properties of TG improve residence time of drug in ocular cavity. TG is used in the formulation of mucoadhesive gels and nanoparticles. Pilocarpine, rufloxacin and ofloxacin have been successfully investigated for ocular drug delivery using $\mathrm{TG}^{[19,21,132]}$. TG has been used as a viscosity modifier and mucoadhesive agent in the preparation of ocular timolol formulations. In rabbit model, TG has improved duration of action of timolol and proved to be suitable for ocular administration in cases of elevated intraocular pressure $^{[133]}$. Further, gentamicin and ofloxacin ophthalmic solutions have been prepared using TG as a mucoadhesive agent and investigated for the bioavailability enhancement 
in rabbit model. The viscous preparation of TG improved the drug absorption and decreased the drug elimination indicating its suitability for the ophthalmic delivery of antibiotics $^{[35]}$. TG prolongs the precorneal residence time of rufloxacin, improves drug residence in the cornea and acts as a vehicle for the ocular treatment of bacterial keratitis in rabbit model ${ }^{[134]}$. TG is also found to be suitable for maintaining wetness in eyes. The study performed by Rolando and Valente (2007) in 30 patients, suggested that the $1 \% \mathrm{TG}$ is suitable for frequent use in the therapy of dry eye syndrome ${ }^{[135]}$. Further, study was designed to investigate the potential clinical benefit of a combination of hyaluronic acid and TG-polysaccharide in managing dry eye disease (DED). Total 49 subjects with DED were used in the study. Patients treated with hyaluronic acid and TG showed statistically significant improvement in the Ocular Surface Disease Index score compared to the baseline and control groups. The results of this clinical trial indicated the combination of hyaluronic acid and TG appears to be effective in improving the symptoms of dry eye ${ }^{[136]}$.

The in situ gelling system of dorzolamide hydrochloride has been formulated using CMTG, xanthan gum, SA and gellan gum in order to improve the precorneal retention and improve ocular bioavailability. All formulations were converted into gel when exposed to artificial tear fluid ( $\mathrm{pH}$ 7.4) within one minute and are found to be pseudoplastic and mucoadhesive in nature, which improves corneal retention of drug. The CMTG based gels showed sustained release of drug over a period of $8 \mathrm{~h}$. Optimized formulations showed good physical stability after sterilization and were found to be nonirritant with no ocular damage in ocular irritancy test on rabbits. Isotonicity studies revealed that formulations are isotonic with that of blood cells. The proposed in situ gel of drug has feasibility to form gel when in contact with the tear fluid and may be a viable alternative to the conventional eye solutions ${ }^{[137]}$.

Dilbaghi and co-workers (2013) have prepared tropicamide loaded nano-aggregates prepared for ophthalmic delivery. TG and Poloxamer 407 were used as polymers. Tropicamide loaded TG nano-aggregates showed high mucoadhesion and a high corneal permeation as compared to commercial formulation ${ }^{[138]}$. Ophthalmic CMTG nanoparticles of tropicamide were prepared by ionotropic gelation method using calcium chloride as crosslinking agent. The concentration of CMTG and crosslinking agent showed positive effect on particle size and drug encapsulation efficiency. The result of ex vivo corneal permeation of tropicamide across isolated goat cornea from CMTG nanosuspension was comparable to the aqueous drug solution. Further, the ex vivo bioadhesion and ocular tolerance test revealed the mucoadhesive nature of the nanoparticles ${ }^{[139]}$.

Table 11: TG and modified TG based ophthalmic drug delivery systems

\begin{tabular}{|c|c|c|c|c|c|}
\hline Therapeutic agent & Formulation type & Technique used & Excipients used & Role of Polymer & Animals used \\
\hline Timolol $^{[133]}$ & Aqueous solution & Simple mixing & TG & $\begin{array}{l}\text { Viscosity modifier, } \\
\text { mucoadhesive }\end{array}$ & Rabbits \\
\hline Timolol ${ }^{[140]}$ & Film & Molding & TG & $\begin{array}{c}\text { Film former, release } \\
\text { modifier }\end{array}$ & Rabbits \\
\hline Gentamicin Ofloxacin ${ }^{[35]}$ & Aqueous solution & Simple mixing & TG & $\begin{array}{l}\text { Viscosity modifier, } \\
\text { mucoadhesive }\end{array}$ & Rabbits \\
\hline Rufloxacin $^{[134]}$ & Aqueous solution & Simple mixing & TG & $\begin{array}{l}\text { Viscosity modifier, } \\
\text { mucoadhesive }\end{array}$ & Rabbits \\
\hline Pilocarpine ${ }^{[132]}$ & In-situ gel & Simple mixing & SA-TG & Improve gel consistency & Rabbits \\
\hline Tropicamide $^{[138]}$ & Nano-aggregates & $\begin{array}{l}\text { Magnetic stirring } \\
\text { with lyophilization }\end{array}$ & TG-Poloxamer 407 & Mucoadhesive & NA \\
\hline Tropicamide $^{[139]}$ & Nanoparticles & IGM with lyophilization & CMTG-CaCl${ }_{2}$ & Mucoadhesive & NA \\
\hline Dorzolamide hydrochloride $^{[137]}$ & In situ gel & Simple mixing & CMTG-XG, CMTG-GG & Gelling agent & Rabbits \\
\hline
\end{tabular}

IGM-Ionotropic gelation method; TG-tamarind gum; SA-sodium alginate; XG-xanthan gum; GG-gellan gum; CMTG- carboxymethyl tamarind gum; NA- not applicable

\subsection{Nasal drug delivery}

TG and CMTG have been used in the development of nasal gels and mucoadhesive thermoreversible gels (see Table 12). Drugs like diazepam, zolmitriptan, ketorolac tromethamine and venlafaxine have been investigated for nasal drug delivery ${ }^{[19,141]}$. Nasal gel of diazepam has been prepared using natural mucoadhesive agent, TG. It has been observed that the mucoadhesive strength, viscosity and gelling property of TG was higher than HPMC and carbopo 1934. The results suggested that due to the presence of numerous carboxyl and hydroxyl groups, TG adopts more favorable macromolecular conformation favorable for mucoadhesion than HPMC and carbopol 934. HPMC may form a weaker bond with mucus, which is due to less number of available hydrogen bonding sites or unfavorable condition for entanglement. The in vitro drug release from TG containing formulation was greater than the synthetic polymers $^{[142]}$.

Zolmitriptan and Ketorolac tromethamine loaded thermoreversible in situ mucoadhesive intranasal gels were prepared for migraine therapy. Thermorevesible gel was prepared by cold method using Poloxamer 407 as a thermoreversible polymer and TG and SA as mucoadhesive polymers. TG containing formulations showed anomalous drug release and were found to be safe for nasal administration. Pharmacokinetic study in 
rabbits showed improved nasal bioavailability of drug over oral route ${ }^{[143]}$. Recently, it has been proved that mucoadhesive microparticles $(10 \mu \mathrm{m})$ of TG can achieve selective deposition and retention of drug in the olfactory mucosa $^{[144]}$.

Thermoreversible gel formed by partially degraded TG has been used for nasal delivery of ondansetron. The partially enzyme degraded TG of $2.5 \% \mathrm{w} / \mathrm{w}$ formed gels at $25-30^{\circ} \mathrm{C}$. The in vitro release of ondansetron hydrochloride from the enzyme degraded TG gels followed Higuchi kinetics over a period of $5 \mathrm{~h}$ at $34^{\circ} \mathrm{C}$ by anomalous transport mechanism. Histological examination of nasal mucosa following a single administration of the gels showed no evidence of mucosal damage. Absolute bioavailability of ondansetron hydrochloride was significantly increased from $28.64 \%$ in case of the oral drug solution to $52.79 \%$ in case of the nasal in situ gel in rabbits. The results of this study suggest the potential of the enzyme-degraded xyloglucan gels as vehicles for nasal delivery of drugs ${ }^{[70]}$.

Table 12: Investigated nasal drug delivery systems based on TG and modified TG

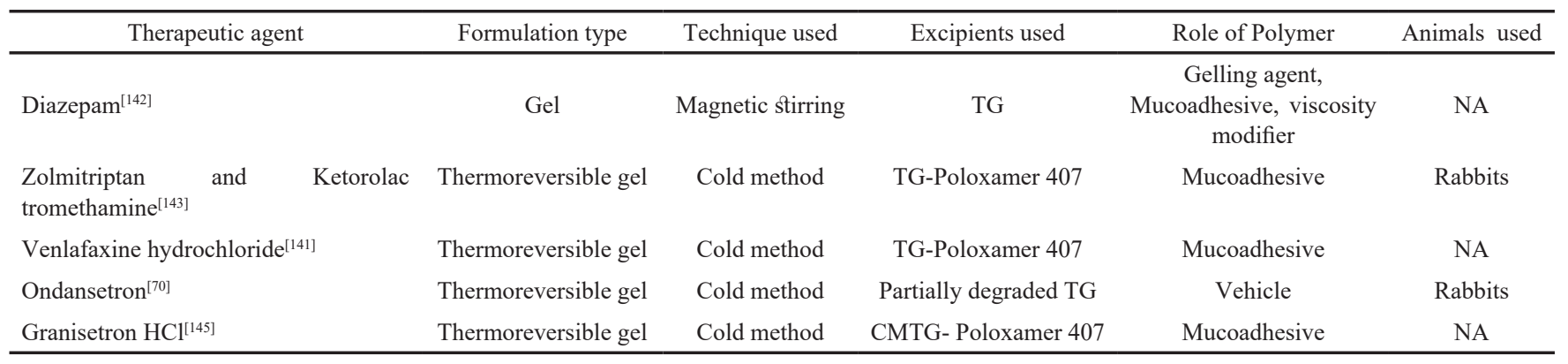

TG-tamarind gum; NA- not applicable

\subsection{Colon targeted drug delivery}

The ability of TG to degrade in colon makes it a suitable polymer for development of colon targeted drug delivery. Ibuprofen drug has been studied using TG for colon targeting. The results of in vitro drug release study indicate that the matrix tablets prepared by using TG are able to carry most of the drug to the colon and restrict the release in upper GIT ${ }^{[146]}$. The tablet coated with chitosanCMTG interpolymer complex has been prepared for colon drug delivery of budesonide. The complex was used as a binder in tableting and tablets were coated with complex. The interpolymer complexed (IPC) film showed swelling in acidic medium as well as in basic medium. High swelling in acidic environment was observed due to the protonation and repulsion in between free ammonium groups of chitosan. The tablets coated with interpolymer complex restricted the drug release at $\mathrm{pH}$ 1.2. From complex, drug was released by erosion of polymers and followed zero order kinetics. The results of in vivo study indicated that the tablets coated with IPC film has ability to inhibit the release of drug in gastric $\mathrm{pH}$ and rapid release is observed between 4 to $8 \mathrm{~h}$ followed by decrease, possibly due to the degradation of polymers in rats colon. From the results, the tablet coated with chitosan-CMTG interpolymer complexed films were found to be efficient to deliver drug in distal part of gastrointestinal tract as expected in colon targeted drug delivery ${ }^{[147]}$

\subsection{Transdermal drug delivery}

TG and CMTG exhibit excellent film-forming ability and can be used in transdermal delivery of drugs (see Table 13). Topical films of TG have been used in wound healing and skin tissue engineering. Iodine loaded tamarind films have been successfully developed to treat wounds ${ }^{[19,21]}$. The ciprofloxacin loaded phase separated films have been prepared by using gelatin and TG or CMTG for skin tissue engineering. Glutaraldehyde was used as crosslinker and polyethylene glycol as plasticizer. The polysaccharide containing films supported better proliferation of human keratinocytes as compared to the control. The stress relaxation study suggested better relaxation properties of CMTG film. Drug loaded films showed good antimicrobial activity. The results indicated that the prepared films may be useful as matrix for skin tissue engineering and controlled drug delivery application $^{[148]}$.

Polyvinyl alcohol and CMTG composite film containing ciprofloxacin has been prepared using glutaraldehyde as crosslinking agent ${ }^{[149]}$. FTIR spectroscopy suggested the occurrence of hydrogen bonding amongst the components of the films. All the films were viscoelastic in nature. Ciprofloxacin loaded films showed excellent antimicrobial property against E. coli, suggesting that the drug is released in its active form. Cell proliferation study using human keratinocytes revealed better cell proliferation in the CMTG containing films as compared to the control (PVA only) film. The study proposed potential application of the PVA-CMTG films in wound dressings and other skin diseases where topical application of the drug is required.

Enzyme degraded TG has been used as sustained release vehicle for the topical delivery of ibuprofen and ketoprofen. It acts as the thermoreversible polymer and forms gels at body temperature when used in the concentration range of 1 to $2 \% \mathrm{w} / \mathrm{v}$, which is too low than the concentration of Poloxamer 407 (25\% w/v). Partially enzyme degraded TG helps to enhance the bioavailabilty of studied drugs than Pluronic F127 gels ${ }^{[67]}$. 
Table 13: Investigated transdermal drug delivery systems of TG and modified TG

\begin{tabular}{|c|c|c|c|c|c|}
\hline Therapeutic agent & Formulation type & Technique used & Excipients used & Role of Polymer & Animals used \\
\hline Iodine $^{[150]}$ & Film & Solution casting & TG-Epichlorohydrin & Film former & Rats \\
\hline Alfuzocin $^{[151]}$ & Film & Solution casting & TG & Film former, release retardant & NA \\
\hline Ciprofloxacin $^{[148]}$ & Phase separated film & Solution casting & $\begin{array}{c}\text { TG-gelatin } \\
\text { CMTG-gelatin } \\
\text { (GA as crosslinker) }\end{array}$ & $\begin{array}{l}\text { Matrix for skin tissue } \\
\text { engineering }\end{array}$ & NA \\
\hline Ciprofloxacin $^{[149]}$ & Films & Solution casting & $\begin{array}{c}\text { CMTG-PVA } \\
\text { (GA as crosslinker) }\end{array}$ & $\begin{array}{l}\text { Matrix for skin tissue } \\
\text { engineering }\end{array}$ & NA \\
\hline Ibuprofen, Ketoprofen ${ }^{[67]}$ & Thermoreversible gel & Homogenization & Enzyme degraded TG & $\begin{array}{c}\text { Gelling agent, sustain release } \\
\text { vehicle }\end{array}$ & NA \\
\hline Itraconazole $\mathrm{e}^{[152]}$ & Microemulsion based gel & Mixing & TG & $\begin{array}{l}\text { Gelling agent, } \\
\text { Bioadhesive }\end{array}$ & NA \\
\hline
\end{tabular}

TG-tamarind gum; CMTG-carboxymethyl tamarind gum; GA- Glutaraldehyde; NA- not applicable

\subsection{Rectal drug delivery}

Partially degraded TG by galactosidase enzyme is used for the development of rectal drug delivery due to its thermoreversible nature. It has been investigated for the delivery of indomethacin and diltiazem. The thermoreversible gel exhibited gelation temperature in the range of 27 to $22{ }^{\circ} \mathrm{C}$. The in vitro drug release from the thermoreversible gels followed Higuchi kinetics over a period of 5 h. Formulated gels showed sustained drug release than the marketed formulation ${ }^{[71]}$.

\subsection{Pulmonary drug delivery}

Partially degraded TG has been used for the preparation of mucoadhesive microspheres of Montelucast for pulmonary delivery. Spray-drying technique was used to prepare microspheres employing lactose monohydrate as carrier for dry powder inhalation (DPI). In vitro characterization of optimized microsphere formulation demonstrates its suitability as dry powder inhalation. A promising in vitro aerosol performance was observed for the developed formulation of DPIs suggesting high deep lung deposition of drug. The data of in vivo studies showed drug residence up to $6 \mathrm{~h}$. It provided high and prolonged drug concentration within lungs after pulmonary administration in rats ${ }^{[153]}$

\subsection{Periodontal drug delivery}

In situ gel of lidocaine has been formulated using poloxamer as a thermoreversible gelling agent and TG as a mucoadhesive polymer, by cold method. The in vitro study depicted the fast onset of drug action but sustained the release $(90 \%)$ till $2 \mathrm{~h}$. It offers an alternative to painful injection therapy of anesthesia during dental surgery, with fast onset of anesthetic action lasting throughout the dental procedure $^{[23]}$.

\subsection{Parenteral drug delivery}

Partially degraded TG has been used in the development of intraperitoneal mitomycin $\mathrm{C}$ injection. It was used as a sustained release vehicle. Intraperitoneal injection of gel resulted in a broad concentration-time profile for drug in both, the ascites and the plasma, compared with a narrow peak and rapid disappearance from both sites when this drug was given i.p. as a solution ${ }^{[154]}$.
Gupta et al., (2015) synthesized thermo-associating polymer by grafting amino terminated poly(ethylene oxideco-propylene oxide) (PEPO) onto CMTG. The grafting was performed by coupling reaction between $\mathrm{NH}_{2}$ groups of PEPO and $\mathrm{COOH}$ groups of CMTG using water-soluble EDC/NHS as coupling agents. The graft copolymer, CMTG-g-PEPO exhibited interesting thermo-associating behavior. The results indicate that the thermo-associating polymer with biodegradable nature of CMTG can have potential applications as smart injectables in controlled release technology and as thickeners in cosmetics and pharmaceutical formulations ${ }^{[155]}$.

\subsection{Miscellaneous applications}

Singh and Kumar, (2011) have prepared CMTG initiated and catalyzed sol-gel polymerization of tetramethoxysilane nanohybrids for immobilizing $\alpha$-amylase for starch hydrolysis. The immobilization improved the affinity and catalytic properties of amylase, besides the enzyme under immobilized state showed more thermal stability. The immobilization using nanohybrids doubled the enzyme activity along with improvement in the working conditions. The nanohybrid improved the overall stability, affinity and catalytic property of $\alpha$-amylase ${ }^{[156]}$.

\section{CONCLUSION}

Tamarind seed is an underutilized raw material in India. The proper use of the tamarind seed may fetch better return to the pulp processing industries that in turn may help the people who gather or even cultivate the tree.

In order to overcome the short comings like processing cost, availability, toxicity and compatibility, there is need to search new excipients. Currently, TG has gained popularity for its utility in the preparation of various pharmaceutical dosage forms. Literature survey reveals that the TG and modified TG have great potential in the development of various drug delivery systems and further research can enlighten its industrial applicability as an excipient. The review demonstrates the possibilities of using TG as promising pharmaceutical excipient in various pharmaceutical formulations.

\section{ACKNOWLEDGEMENT}

We are immensely obliged and thankful to Principal, 
Government College of Pharmacy, Karad. We also extend our gratitude to President, Yashoda Technical Campus, Satara for catering legitimate facilities for carrying out the work.

\section{CONFLICT OF INTERESTS}

There are no conflicts of interest.

\section{REFERENCES}

1. P. Laurienzo, J.C. Fernandes, S. Colliec-Jouault, J.H. Fitton, The use of natural polysaccharides as biomaterials, Biomed Res. Int. 2015 (2015) 1-2. doi: $10.1155 / 2015 / 242378$.

2. K.K. Mali, R.J. Dias, V.S. Ghorpade, V.D. Havaldar, Sodium alginate microspheres containing multicomponent inclusion complex of domperidone, Lat. Am. J. Pharm. 29 (2010) 1199-207.

3. V.D. Havaldar, A.S. Kulkarni, R.J. Dias, N.H. Aloorkar, K.K. Mali, Floating matrix tablets of atenolol: Formulation and in vitro evaluation, Asian J. Pharm. 3 (2009) 286-291. doi:10.4103/0973-8398.59952.

4. S. Gupta, S. Jain, G. Rao, V. Gupta, R. Puri, Tamarind kernel gum: An upcoming natural polysaccharide, Syst. Rev. Pharm. 1 (2010) 50-54 doi:10.4103/0975-8453.59512.

5. J. Garner, K. Park, Chemically modified natural polysaccharides to form gels, in: Polysaccharides, Springer International Publishing, Cham, 2015: pp. 1555-1582. doi:10.1007/978-3-319-16298-0_31.

6. K.Y. Lee, D.J. Mooney, Alginate: properties and biomedical applications, Prog. Polym. Sci. 37 (2012) 106-126. doi:10.1016/j. progpolymsci.2011.06.003.Alginate.

7. A.B. Jindal, M.N. Wasnik, H.A. Nair, Synthesis of thiolated alginate and evaluation of mucoadhesiveness, cytotoxicity and release retardant properties., Indian J. Pharm. Sci. 72 (2010) 766-74. doi:10.4103/0250-474X.84590

8. S.N. Murthy, S.R.R. Hiremath, K.L.K. Paranjothy, Evaluation of carboxymethyl guar films for the formulation of transdermal therapeutic systems, Int. J. Pharm. 272 (2004) 11-18. doi:10.1016/j. ijpharm.2003.11.019.

9. R.T. Thimma, S. Tammishetti, Barium chloride crosslinked carboxymethyl guar gum beads for gastrointestinal drug delivery, J. Appl. Polym. Sci. 82 (2001) 3084-3090. doi:10.1002/app.2164.

10. K.S. Soppimath, A.R. Kulkarni, T.M. Aminabhavi, Chemically modified polyacrylamide-g-guar gum-based crosslinked anionic microgels as $\mathrm{pH}$ - sensitive drug delivery systems: Preparation and characterization, J. Control. Release. 75 (2001) 331-345. doi:10.1016/S0168-3659(01)00404-7.

11. U.S. Toti, T.M. Aminabhavi, Modified guar gum matrix tablet for controlled release of diltiazem hydrochloride, J. Control. Release. 95 (2004) 567 577. doi:10.1016/j.jconrel.2003.12.019.

12. H. Jiang, Y. Wang, Q. Huang, Y. Li, C. Xu, K. Zhu, W. Chen, Biodegradable hyaluronic acid/Ncarboxyethyl chitosan/protein ternary complexes as implantable carriers for controlled protein release, Macromol. Biosci. 5 (2005) 1226-1233. doi:10.1002/mabi.200500126.

13. S.A. Agnihotri, N.N. Mallikarjuna, T.M. Aminabhavi, Recent advances on chitosan-based micro- and nanoparticles in drug delivery, $\mathrm{J}$. Control. Release. 100 (2004) 5-28. doi:10.1016/j. jconrel.2004.08.010.

14. R. Sharma, M. Ahuja, Thiolated pectin: Synthesis, characterization and evaluation as a mucoadhesive polymer, Carbohydr. Polym. 85 (2011) 658-663. doi:10.1016/j.carbpol.2011.03.034.

15. M.S. Bhatia, R. Deshmukh, P. Choudhari, N.M. Bhatia, Chemical modification of pectins, characterization and evaluation for drug delivery, Sci. Pharm. 76 (2008) 775-784. doi:10.3797/ scipharm.0805-23.

16. S. Maiti, S. Ray, B. Sa, Controlled delivery of bovine serum albumin from carboxymethyl xanthan microparticles Xanthan microparticles, Pharm. Dev. Technol. 14 (2009) 165-172. doi:10.1080/10837450802498878.

17. R.C. Mundargi, S.A. Patil, T.M. Aminabhavi, Evaluation of acrylamide-grafted-xanthan gum copolymer matrix tablets for oral controlled delivery of antihypertensive drugs, Carbohydr. Polym. 69 (2007) 130-141. doi:10.1016/j. carbpol.2006.09.007.

18. C.S. Kumar, S. Bhattacharya, Tamarind seed: properties, processing and utilization., Crit. Rev. Food Sci. Nutr. 48 (2008) 1-20. doi:10.1080/10408390600948600

19. A.K. Nayak, D. Pal, Tamarind seed polysaccharide: An emerging excipient for pharmaceutical use, Indian J. Pharm. Educ. Res. 51 (2017) S136-S146. doi:10.5530/ijper.51.2s.60.

20. G.R. Savur, A. Sreenivasan, Isolation and characterization of tamarind seed (Tamarindus indica L.) Polysaccharide, J. Biol. Chem. 172 (1948) 501-509.

21. J. Joseph, S. Kanchalochana, G. Rajalakshmi, V. Hari, R. Durai, Tamarind seed polysaccharide: A 
promising natural excipient for pharmaceuticals, Int. J. Green Pharm. 6 (2012) 270-278. doi:10.4103/0973-8258.108205.

22. A.D. Kulkarni, A.A. Joshi, C.L. Patil, P.D. Amale, H.M. Patel, S.J. Surana, V.S. Belgamwar, K.S. Chaudhari, C. V. Pardeshi, Xyloglucan: A functional biomacromolecule for drug delivery applications, Int. J. Biol. Macromol. 104 (2017) 799-812. doi:10.1016/j.ijbiomac.2017.06.088.

23. A.P. Pandit, V. V. Pol, V.S. Kulkarni, Xyloglucan based in situ gel of lidocaine $\mathrm{HCl}$ for the treatment of periodontosis, J. Pharm. 2016 (2016) 1-9. doi:10.1155/2016/3054321.

24. T. Saikia, J. Ali, B. Das, Isolation and characterisation of tamarind seed polysaccharideA natural release retardant, Int. J. Curr. Pharm. Res. 9 (2017) 114-117.

25. D. Kulkarni, A. Dwivedi, J. Sarin, Tamarind seed polyose: A potential polysaccharide for sustained release of verapamil hydrochloride as a model drug, Indian J. Pharm. Sci. 59 (1997) 1-7.

26. M. Sano, E. Miyata, S. Tamano, A. Hagiwara, N. Ito, T. Shirai, Lack of carcinogenicity of tamarind seed polysaccharide in B6C3F1 mice, Food Chem. Toxicol. 34 (1996) 463-467. doi:10.1016/02786915(96)87356-X.

27. J.T. Heimbach, H. Egawa, P.A. Marone, M.R. Bauter, E. Kennepohl, Tamarind seed polysaccharide: A 28-day dietary study in SpragueDawley rats, Int. J. Toxicol. 32 (2013) 198-208. doi:10.1177/1091581813484069.

28. R. Kumar, S.R. Patil, M.B. Patil, M.S. Paschapur, R. Mahalaxmi, Isolation and evaluation of the emulsifying properties of tamarind seed polysaccharide on castor oil emulsion., Der Pharm. Lett. 2 (2010) 518-527.

29. F. Nakamura, R. Ohta, Y. Machida, T. Nagai, In vitro and in vivo nasal mucoadhesion of some water-soluble polymers, Int. J. Pharm. 134 (1996) 173-181. doi:10.1016/0378-5173(95)04416-7.

30. P. Bassi, G. Kaur, Polymeric films as a promising carrier for bioadhesive drug delivery: Development, characterization and optimization, Saudi Pharm. J. 25 (2017) 32-43. doi:10.1016/j.jsps.2015.06.003.

31. K.K. Kumar, G. Prakash, R. Nagakishore, In vitro and in vivo biodegradation study of tamarind kernel powder (Xyloglucan), Indian J. Nov. Drug Deliv. 8 (2016) 212-216.

32. S. Burgalassi, L. Panichi, M.F. Saettone, J. Jacobsen, M.R. Rassing, Development and in vitro/in vivo testing of mucoadhesive buccal patches releasing benzydamine and lidocaine, Int. J. Pharm. 133 (1996) 1-7. doi:10.1016/03785173(95)04392-6.

33. S. Samantray, A.K. Khillar, U.K. Parida, B.K Bindhani, Synthesis of polysaccharide PST001 isolated from the seed kernel of Tamarindus indica L. and its biomedical applications, Int. J. Res. Pharm. Biomed. Sci. 4 (2013) 833-840.

34. J. Kochumalayil, H. Sehaqui, Q. Zhou, L. a. Berglund, Tamarind seed xyloglucan - a thermostable high-performance biopolymer from non-food feedstock, J. Mater. Chem. 20 (2010) 4321. doi:10.1039/c0jm00367k.

35. E. Ghelardi, A. Tavanti, F. Celandroni, A. Lupetti, C. Blandizzi, E. Boldrini, M. Campa, S. Senesi, Effect of a novel mucoadhesive polysaccharide obtained from tamarind seeds on the intraocular penetration of gentamicin and ofloxacin in rabbits. J. Antimicrob. Chemother. 46 (2000) 831-834.

36. G. Uccello-Barretta, S. Nazzi, F. Balzano, M. Sansò, A nuclear magnetic resonance approach to the comparison of mucoadhesive properties of polysaccharides for ophthalmic uses, Int. J. Pharm. 406 (2011) 78-83. doi:10.1016/j. ijpharm.2010.12.032.

37. S. Bhattacharya, S. Bal, R.K. Mukherjee, S. Bhattacharya, Rheological behavior of tamarind (Tamarindus indica) kernel power (TKP) suspension, J. Food Eng. 13 (1991) 151-158.

38. J.A. Salazar-Montoya, E.G. Ramos-Ramírez, V.A. Delgado-Reyes, Changes of the dynamic properties of tamarind (Tamarindus indica) gel with different saccharose and polysaccharide concentrations, Carbohydr. Polym. 49 (2002) 387391. doi:10.1016/S0144-8617(01)00337-X.

39. S. Yamanaka, Y. Yuguchi, H. Urakawa, K. Kajiwara, M. Shirakawa, K. Yamatoya, Gelation of tamarind seed polysaccharide xyloglucan in the presence of ethanol, Food Hydrocoll. 14 (2000) 125-128. doi:10.1016/S0268-005X(99)00057-0.

40. M. Sharma, D. Mondal, C. Mukesh, K. Prasad, Preparation of tamarind gum based soft ion gels having thixotropic properties, Carbohydr. Polym. 102 (2014) 467-471. doi:10.1016/j. carbpol.2013.11.063.

41. R. Singh, R. Malviya, P. Kumar Sharma, Extraction and characterization of tamarind seed polysaccharide as a pharmaceutical excipient, Pharmacogn. J. 3 (2011) 17-19. doi:10.5530/ pj.2011.20.4.

42. V. Sharma, P. Patnaik, K. Senthilguru, S.K. Nayak, I. Syed, V.K. Singh, P. Sarkar, G. Thakur, 
K. Pal, Preparation and characterization of novel tamarind gum-based hydrogels for antimicrobial drug delivery applications, Chem. Pap. (2018). doi:10.1007/s11696-018-0414-X.

43. B. Choudhary, S.R. Paul, S.K. Nayak, V.K. Singh, A. Anis, K. Pal, Understanding the effect of functionalized carbon nanotubes on the properties of tamarind gum hydrogels, Polym. Bull. (2018). doi:10.1007/s00289-018-2300-7.

44. A.K. Shukla, R.S. Bishnoi, M. Kumar, V. Fenin, C.P. Jain, Applications of tamarind seeds polysaccharide-based copolymers in controlled drug delivery: An overview, Asian J. Pharm. Pharmacol. 4 (2018) 23-30.

45. S. Sumathi, A.R. Ray, Release behaviour of drugs from tamarind seed polysaccharide tablets, J. Pharm. Pharm. Sci. 5 (2002) 12-18.

46. A.K. Nayak, D. Pal, Functionalization of tamarind gum for drug delivery, in: Funct. Biopolym., 2018: pp. 25-56. doi:10.1007/978-3-319-66417-0_2.

47. H. Prabhanjan, Studies on modified tamarind kernel powder Part I: Preparation and physicochemical properties of sodium salt of carboxymethyl derivatives, Starke. 11 (1989) 409-414.

48. P. Rao, R. Beri, Acetylation of tamarind seed jellose, Proc. Indian Acad. Sci. - Sect. A. 42 (1955) 199-203. doi:10.1007/BF03053508.

49. H. Prabhanjan, S.Z. Ali, Studies on rheological properties of tamarind kernel powder, its derivatives and their blends with maize starch, Carbohydr. Polym. 28 (1995) 245-253. doi:10.1016/01448617(95)00106-9.

50. G. Kaur, M. Mahajan, P. Bassi, Derivatized polysaccharides: Preparation, characterization, and application as bioadhesive polymer for drug delivery, Int. J. Polym. Mater. 62 (2013) 475-481. doi:10.1080/00914037.2012.734348.

51. P. Lang, G. Masci, M. Dentini, V. Crescenzi, D. Cooke, M.J. Gidley, C. Fanutti, J.S.G. Reid, Tamarind seed polysaccharide: preparation, characterisation and solution properties of carboxylated, sulphated and alkylaminated derivatives, Carbohydr. Polym. 17 (1992) 185198. doi:10.1016/0144-8617(92)90003-9.

52. S. Pal, G. Sen, S. Mishra, R.K. Dey, U. Jha, Carboxymethyl tamarind: Synthesis, characterization and its application as novel drugdelivery agent, J. Appl. Polym. Sci. 110 (2008) 392-400. doi:10.1002/app.28455.

53. P. Goyal, V. Kumar, P. Sharma, Carboxymethylation of tamarind kernel powder, Carbohydr.
Polym. 69 (2007) 251-255. doi:10.1016/j. carbpol.2006.10.001.

54. K.K. Mali, S.C. Dhawale, R.J. Dias, Synthesis and characterization of hydrogel films of carboxymethyl tamarind gum using citric acid, Int. J. Biol. Macromol. 105 (2017) 463-470. doi:10.1016/j.ijbiomac.2017.07.058.

55. B. Ponnikornkit, C. Ngamsalak, K. Huanbutta, W. Sittikijyothin, Swelling behaviour of carboxymethylated tamarind gum, Adv. Mater. Res. 1060 (2015) 137-140. doi:10.4028/www. scientific.net/AMR.1060.137.

56. P. Goyal, V. Kumar, P. Sharma, Cyanoethylation of tamarind kernel powder, Starch/Staerke. 60 (2008) 41-47. doi:10.1002/star.200700609.

57. P. Lang, G. Masci, M. Dentini, V. Crescenzi, D. Cooke, M.J. Gidley, C. Fanutti, J.S.G. Reid, Tamarind seed polysaccharide: preparation, characterisation and solution properties of carboxylated, sulphated and alkylaminated derivatives, Carbohydr. Polym. 17 (1992) 185198. doi:10.1016/0144-8617(92)90003-9.

58. C.K. Simi, T.E. Abraham, Physico chemical properties of aminated tamarind xyloglucan, Colloids Surfaces B Biointerfaces. 81 (2010) 513520. doi:10.1016/j.colsurfb.2010.07.051.

59. M. Mahajan, G. Kaur, Formulation and evaluation of buccal bioadhesive patches employing derivatized tamarind seed polysaccharide, Int. J. Polym. Mater. 63 (2014) 310-314. doi:10.1080/0 0914037.2013.845184.

60. H. Kaur, S. Yadav, M.Ahuja, N. Dilbaghi, Synthesis, characterization and evaluation of thiolated tamarind seed polysaccharide as a mucoadhesive polymer, Carbohydr. Polym. 90 (2012) 1543 1549. doi:10.1016/j.carbpol.2012.07.028.

61. A. Madgulkar, M.R. Bhalekar, A.A. Dikpati, Improving oral bioavailability of acyclovir using nanoparticulates of thiolated xyloglucan, Int. J. Biol. Macromol. 89 (2016) 689-699. doi:10.1016/j. ijbiomac.2016.02.007.

62. A.R. Madgulkar, M.R. Bhalekar, A.A. Kadam, Improvement of oral bioavailability of lopinavir without co-administration of ritonavir using microspheres of thiolated xyloglucan, AAPS PharmSciTech. 19 (2018) 293-302. doi:10.1208/ s12249-017-0834-x.

63. M. Bhalekar, S. Sonawane, S. Shimpi, Synthesis and characterization of a cysteine xyloglucan conjugate as mucoadhesive polymer, Brazilian 
J. Pharm. Sci. 49 (2013) 285-292. doi:10.1590/ S1984-82502013000200010.

64. B. Sravani, R. Deveswaran, S. Bharath, B. V Basavaraj, V. Madhavan, Release characteristics of drugs from cross linked tamarind seed polysaccharide matrix tablets, Pelagia Res. Libr. 2 (2011) 67-76.

65. S. Jana, D. Lakshman, K.K. Sen, S.K. Basu, Development and evaluation of epichlorohydrin cross-linked mucoadhesive patches of tamarind seed polysaccharide for buccal application, Int. J. Pharm. Sci. Drug Res. 2 (2010) 193-198.

66. M. Shirakawa, K. Yamatoya, K. Nishinari, Tailoring of xyloglucan properties using an enzyme, Food Hydrocoll. 12 (1998) 25-28. doi:10.1016/S0268005X(98)00052-6.

67. A. Takahashi, S. Suzuki, N. Kawasaki, W. Kubo, S. Miyazaki, R. Loebenberg, J. Bachynsky, D. Attwood, Percutaneous absorption of nonsteroidal anti-inflammatory drugs from in situ gelling xyloglucan formulations in rats, Int. J. Pharm. 246 (2002) 179-186. doi:10.1016/S03785173(02)00394-0.

68. S. Miyazaki, K. Endo, N. Kawasaki, W. Kubo, H. Watanabe, D. Attwood, Oral sustained delivery of paracetamol from in situ gelling xyloglucan formulations, Drug Dev. Ind. Pharm. 29 (2003) 113-119. doi:10.1081/DDC-120016718.

69. S. Miyazaki, N. Kawasaki, W. Kubo, K. Endo, D. Attwood, Comparison of in situ gelling formulations for the oral delivery of cimetidine, Int. J. Pharm. 220 (2001) 161-168. doi:10.1016/ S0378-5173(01)00669-X.

70. H.S. Mahajan, V. Tyagi, G. Lohiya, P. Nerkar, Thermally reversible xyloglucan gels as vehicles for nasal drug delivery, Drug Deliv. 19 (2012) 270-276. doi:10.3109/10717544.2012.704095.

71. N. Kawasaki, R. Ohkura, S. Miyazaki, Y. Uno, S. Sugimoto, D. Attwood, Thermally reversible xyloglucan gels as vehicles for rectal drug delivery, Int. J. Pharm. 181 (1999) 227-234. doi:10.1016/ S0378-5173(99)00026-5.

72. S. Miyazaki, S. Suzuki, N. Kawasaki, K. Endo, A. Takahashi, D. Attwood, In situ gelling xyloglucan formulations for sustained release ocular delivery of pilocarpine hydrochloride, Int. J. Pharm. 229 (2001) 29-36. doi:10.1016/S03785173(01)00825-0.

73. C.K. Simi, T.E. Abraham, Transparent xyloglucanchitosan complex hydrogels for different applications, Food Hydrocoll. 24 (2010) 72-80. doi:10.1016/j.foodhyd.2009.08.007.

74. S. Ghosh, S. Pal, Modified tamarind kernel polysaccharide: A novel matrix for control release of aspirin, Int. J. Biol. Macromol. 58 (2013) 296300. doi:10.1016/j.ijbiomac.2013.04.002.

75. M. Ahuja, S. Kumar, A. Kumar, Tamarind seed polysaccharide-g-poly(n-vinyl-2-pyrrolidone): Microwave-assisted synthesis, characterization, and evaluation as mucoadhesive polymer, Int. J. Polym. Mater. Polym. Biomater. 62 (2013) 544549. doi:10.1080/00914037.2012.761624.

76. M.M. Ahuja, P. Verma, MW-assisted synthesis of carboxymethyl tamarind kernel polysaccharideg-polyacrylonitrile: optimization and characterization., Carbohydr. Polym. 113 (2014) 532-8. doi:10.1016/j.carbpol.2014.07.041.

77. N. Kawasaki, R. Ohkura, S. Miyazaki, Y. Uno, S. Sugimoto, D. Attwood, Thermally reversible xyloglucan gels as vehicles for oral drug delivery, Int. J. Pharm. 181 (1999) 227-234. doi:10.3109/10 717544.2012.704095.

78. S. Miyazaki, N. Kawasaki, K. Endo, D. Attwood, Oral sustained delivery of theophylline from thermally reversible xyloglucan gels in rabbits, J. Pharm. Pharmacol. 53 (2001) 1185-1191. doi:10.1211/0022357011776621.

79. R. Malviya, P. Srivastava, U. Kumar, C.S. Bhargava, P.K. Sharma, Formulation and comparison of suspending properties of different natural polymers using paracetamol suspension, Int. J. Drug Dev. Res. 2 (2010) 886-891.

80. R. Deveswaran, S. Bharath, S. Furtado, S. Abraham, B. V Basavaraj, V. Madhavan, Isolation and evaluation of tamarind seed polysaccharide as a natural suspending agent, Int. J. Pharm. Biol. Arch. 1 (2010) 360-363.

81. K. Huanbutta, T. Sangmin, W. Sittikijyothin, Development of tamarind seed gum as dry binder in formulation of diclofenac sodium tablets, Walailak J. Sci. Technol. 13 (2016) 863-874.

82. D. Kulkarni, A.K. Dwivedi, S. Singh, Performance evaluation of tamarind seed polyose as a binder and in sustained release formulations of low drug loading, Indian J. Pharm. Sci. 60 (1998) 50-53.

83. M.K. Saha, G.T. Kulkarni, B. Suresh, Development of sustained release bilayered tablets of diclofenac sodium using natural hydrogel as matrix material, J. Chronother. Drug Deliv. 4 (2013) 53-64.

84. K. Ganesan, S.K. Rajaram, A. Chinnathambi, V. Murugesan, K. Muruganantham, T.R. Amanullah, I.S. Barthelomai, S. Chinnasamy, A sustained release of tablet granules associated with $\mathrm{ZnS}$ nanocrystals using tamarind seed polysaccharide, J. Appl. Pharm. Sci. 3 (2013) S44-S47. doi:10.7324/ JAPS.2013.34.S7. 
85. K. Huanbutta, T. Sangnim, W. Sittikijyothin, Physicochemical characterization of gum from tamarind seed: Potential for pharmaceutical application, Asian J. Pharm. Sci. 11 (2016) 176177. doi:10.1016/j.ajps.2015.11.051.

86. B.S. Rao, S.. Kulkarni, P. Patil, C. Surpur, Design and characterization of sustained release aceclofenac matrix tablets containing tamarind seed polysaccharide, Asian J. Pharm. Technol. 1 (2011) 17-21.

87. S. Sumathi, A.R. Ray, Role of modulating factors on release of caffeine from tamarind seed polysaccharide tablets, Trends Biomater. Artif. Organs. 17 (2003) 41-46.

88. R. Kulkarni, A. Shah, R. Boppana, Development and evaluation of xyloglucan matrix tablets containing naproxen, Asian J. Pharm. 2 (2008) 102-105. doi:10.4103/0973-8398.42496.

89. M. Rajab, M. Jouma, R.H.H. Neubert, M. Dittgen, Influence of water-soluble polymers on the in vitro performance of floating mucoadhesive tablets containing metformin, Drug Dev. Ind. Pharm. 40 (2014) 879-885. doi:10.3109/03639045.2013.789 052.

90. R.K. Dey, G.S. Tiwary, T. Patnaik, U. Jha, Controlled release of 5-aminosalicylic acid from a new $\mathrm{pH}$ responsive polymer derived from tamarind seed polysaccharide, acrylic acid, and polyamidoamine, Polym. Bull. 66 (2011) 583-598. doi:10.1007/s00289-010-0294-X.

91. A.R. Madgulkar, M.R. Bhalekar, R.R. Padalkar, M.Y. Shaikh, Optimization of carboxymethylxyloglucan-based tramadol matrix tablets using simplex centroid mixture design, J. Pharm. 2013 (2013) 1-11. doi:10.1155/2013/396468.

92. M. Rajab, A. Tounsi, M. Jouma, R.H.H. Neubert, M. Dittgen, Influence of tamarind seed gum derivatives on the in vitro performance of gastro-retentive tablets based on hydroxypropylmethylcellulose., Pharmazie. 67 (2012) 956-957. doi:10.1691/ ph.2012.2042.

93. M.R. Bhalekar, R. V. Bargaje, P.G. Upadhaya, A.R. Madgulkar, S.J. Kshirsagar, Formulation of mucoadhesive gastric retentive drug delivery using thiolated xyloglucan, Carbohydr. Polym. 136(2016) 537-542. doi:10.1016/j.carbpol.2015.09.064.

94. A.P. Pandit, K. Kumari, P. Waychal, K. Khandelwal, Tamarind seed xyloglucan-based multilayer matrix tablet of tramadol hydrochloride for dual-release, Drug Deliv. Lett. 5 (2015) 63-71.

95. M. Razavi, S. Nyamathulla, H. Karimian, S.Z. Moghadamtousi, M.I. Noordin, Hydrogel polysaccharides of tamarind and xanthan to formulate hydrodynamically balanced matrix tablets of famotidine, Molecules. 19 (2014) 13909-13931. doi:10.3390/molecules190913909.

96. K.K. Mali, S.C. Dhawale, Design and optimization of modified tamarind gum-based floatingbioadhesive tablets of verapamil hydrochloride, Asian J. Pharm. 10 (2016) 2-8. doi:10.22377/ajp. v10i04.862.

97. S. Jana, A. Saha, A.K. Nayak, K.K. Sen, S.K. Basu, Aceclofenac-loaded chitosan-tamarind seed polysaccharide interpenetrating polymeric network microparticles, Colloids Surfaces B Biointerfaces. 105 (2013) 303-309. doi:10.1016/j. colsurfb.2013.01.013.

98. S. Jana, K.K. Sen, S.K. Basu, In vitro aceclofenac release from IPN matrix tablets composed of chitosan-tamarind seed polysaccharide, Int. J. Biol. Macromol. 65 (2014) 241-245. doi:10.1016/j. ijbiomac.2014.01.037.

99. R. V Kulkarni, V. V Baraskar, V. V Alange, A.A. Naikawadi, B. Sa, Controlled release of an antihypertensive drug through interpenetrating polymer network hydrogel tablets of tamarind seed polysaccharide and sodium alginate, J. Macromol. Sci. Part B-Physics. 52 (2013) 1636-1650. doi:10. 1080/00222348.2013.789327.

100.R. V. Kulkarni, S. Mutalik, B.S. Mangond, U.Y. Nayak, Novel interpenetrated polymer network microbeads of natural polysaccharides for modified release of water soluble drug: In-vitro and in-vivo evaluation, J. Pharm. Pharmacol. 64 (2012) 530 540. doi:10.1111/j.2042-7158.2011.01433.x.

101.S. Jana, R. Sharma, S. Maiti, K.K. Sen, Interpenetrating hydrogels of O-carboxymethyl Tamarind gum and alginate for monitoring delivery of acyclovir, Int. J. Biol. Macromol. 92 (2016) 1034-1039. doi:10.1016/j.ijbiomac.2016.08.017.

102.S. Jana, A. Banerjee, K.K. Sen, S. Maiti, Gelatincarboxymethyl tamarind gum biocomposites: In vitro characterization and anti-inflammatory pharmacodynamics, Mater. Sci. Eng. C. 69 (2016) 478-485. doi:10.1016/j.msec.2016.07.008.

103.K.K. Mali, S.C. Dhawale, R.J. Dias, V.D. Havaldar, P.R. Kavitake, Interpenetrating networks of carboxymethyl tamarind gum and chitosan for sustained delivery of aceclofenac, Marmara Pharm. J. 21 (2017) 771-782. doi:10.12991/mpj.2017.20.

104.V.S. Ghorpade, A.V. Yadav, R.J. Dias, K.K. Mali, S.S. Pargaonkar, P.V. Shinde, N.S. Dhane, Citric acid crosslinked carboxymethylcellulosepoly(ethylene glycol) hydrogel films for delivery of poorly soluble drugs, Int. J. Biol. Macromol. 118 (2018) 783-791. doi:10.1016/j. ijbiomac.2018.06.142.

105.K.K. Mali, S.C. Dhawale, R.J. Dias, V.S. Ghorpade, 
N.S. Dhane, Development of vancomycin-loaded polysaccharide-based hydrogel wound dressings: In vitro and in vivo evaluation, Asian J. Pharm. 12 (2018) 94-105.

106.G.S. Shaw, K. Uvanesh, S.N. Gautham, V. Singh, K. Pramanik, N. Kumar, K. Pal, Development and characterization of gelatin-tamarind gum / carboxymethyl tamarind gum based phaseseparated hydrogels : a comparative study, Des. Monomers Polym. 18 (2015) 434-450. doi:10.10 $80 / 15685551.2015 .1041075$.

107.K.K. Mali, S.C. Dhawale, R.J. Dias, N.S. Dhane, V.S. Ghorpade, Citric acid crosslinked carboxymethyl cellulose-based composite hydrogel films for drug delivery, Indian J. Pharm. Sci. 80 (2018) 657-667.

108.M.M. Ahuja, Metronidazole loaded carboxymethyl tamarind kernel polysaccharide-polyvinyl alcohol cryogels: Preparation and characterization, Int. J. Biol. Macromol. 72 (2015) 931-938. doi:10.1016/j. ijbiomac.2014.09.040.

109.S. Sanyasi, A. Kumar, C. Goswami, A. Bandyopadhyay, L. Goswami, A carboxy methyl tamarind polysaccharide matrix for adhesion and growth of osteoclast-precursor cells, Carbohydr. Polym. 101 (2014) 1033-1042. doi:10.1016/j. carbpol.2013.10.047.

110.J.H. Trivedi, Synthesis, characterization, and swelling behavior of superabsorbent hydrogel from sodium salt of partially carboxymethylated tamarind kernel powder- g -PAN, J. Appl. Polym. Sci. 129 (2013) 1992-2003. doi:10.1002/ app.38910.

111. G.T. Kulkarni, K. Gowthamarajan, R.R. Dhobe, F. Yohanan, B. Suresh, Development of controlled release spheroids using natural polysaccharide as release modifier., Drug Deliv. 12 (2005) 201-206. doi:10.1080/10717540590952537.

112.D. V Gowda, N. Mahammed, D.M. Vishnu, Design and evaluation of carboxymethyl tamarind kernel polysaccharide (CMTKP) controlled release spheroids/pellets and investigating the influence of compression, Int. J. Pharm. Pharm. Sci. 6 (2014) 103-109.

113.S. Kshirsagar, A.P. Pandit, Curcumin pellets of carboxymethylated tamarind seed polysaccharide for the treatment of inflammatory bowel disease, Drug Deliv. Lett. 8 (2018) 000-000. doi:10.2174/2 210303107666171106143357.

114. S.S. Muley, T. Nandgude, S. Poddar, Formulation and optimization of Lansoprazole pellets using factorial design prepared by extrusionspheronization technique using Carboxymethyl tamarind kernel powder., Recent Pat. Drug Deliv. Formul. 2 (2017) 1-8. doi:10.2174/187221131166 6170113150248 .

115.A.P. Pandit, P.D. Waychal, A.S. Sayare, V.C Patole, Carboxymethyl tamarind seed kernel polysaccharide formulated into pellets to target at colon, Indian J. Pharm. Educ. Res. 52 (2018) 363-373. doi:10.5530/ijper.52.3.42.

116.A.K. Nayak, D. Pal, Ionotropically-gelled mucoadhesive beads for oral metformin $\mathrm{HCl}$ delivery: Formulation, optimization and antidiabetic evaluation, J. Sci. Ind. Res. (India). 72 (2013) 15-22.

117.A.K. Nayak, D. Pal, K. Santra, Tamarind seed polysaccharide-gellan mucoadhesive beads for controlled release of metformin $\mathrm{HCl}$, Carbohydr. Polym. 103 (2014) 154-163. doi:10.1016/j. carbpol.2013.12.031.

118. A.K. Nayak, D. Pal, K. Santra, Development of calcium pectinate-tamarind seed polysaccharide mucoadhesive beads containing metformin $\mathrm{HCl}$, Carbohydr. Polym. 101 (2014) 220-230. doi:10.1016/j.carbpol.2013.09.024.

119. A.K. Nayak, D. Pal, Development of pH-sensitive tamarind seed polysaccharide-alginate composite beads for controlled diclofenac sodium delivery using response surface methodology, Int. J. Biol. Macromol. 49 (2011) 784-793. doi:10.1016/j. ijbiomac.2011.07.013.

120.H. Bera, S. Boddupalli, S. Nandikonda, S. Kumar, A.K. Nayak, Alginate gel-coated oilentrapped alginate-tamarind gum-magnesium stearate buoyant beads of risperidone, Int. J. Biol. Macromol. 78 (2015) 102-111. doi:10.1016/j. ijbiomac.2015.04.001.

121.C.M. Setty, A.S. Deshmukh, A.M. Badiger, Hydrolyzed polyacrylamide grafted carboxymethylxyloglucan based microbeads for $\mathrm{pH}$ responsive drug delivery, Int. J. Biol. Macromol. 67 (2014) 28-36. doi:10.1016/j. ijbiomac.2014.03.005.

122.D. Pal, A.K. Nayak, Novel tamarind seed polysaccharide-aginate mucoadhesive microspheres for oral gliclazide delivery: in vitroin vivo evaluation, Drug Deliv. 19 (2012) 123-131. doi:10.3109/10717544.2012.657717.

123.S. Sonawane, M. Bhalekar, S. Shimpi, Preparation and evaluation of microspheres of xyloglucan and its thiolated xyloglucan derivative., Int. J. Biol. Macromol. 69 (2014) 499-505. doi:10.1016/j. ijbiomac.2014.05.070.

124.P. Saikia, B. Sahu, S. Dash, Mucoadhesive 
nanoparticles from tamarind seed polysaccharides for sustained delivery of anticancer drug irinotecan, Asian J. Pharm. 7 (2013) 163-169. doi:10.4103/0973-8398.128884.

125.N. Dilbaghi, H. Kaur, M. Ahuja, P. Arora, S. Kumar, Synthesis and evaluation of ciprofloxacin-loaded carboxymethyl tamarind kernel polysaccharide nanoparticles, J. Exp. Nanosci. 9 (2014) 10151025. doi:10.1080/17458080.2013.771244.

126.S. Sanyasi, R.K. Majhi, S. Kumar, M. Mishra, A. Ghosh, M. Suar, P.V. Satyam, H. Mohapatra, C. Goswami, L. Goswami, Polysaccharide-capped silver nanoparticles inhibit biofilm formation and eliminate multi-drug-resistant bacteria by disrupting bacterial cytoskeleton with reduced cytotoxicity towards mammalian cells, Sci. Rep. 6 (2016) 24929. doi:10.1038/srep24929.

127.A. Satle, S. Agrawal, Solubility enhancement potential of tamarind seed polysaccharide as pharmaceutical excipient, Int. J. Curr. Pharm. Res. 4 (2012) 67-73

128.G. V Babu, V. Gowrisankar, K. Himasankar, K. V Murthy, Studies on the applicability of tamarind kernel powder as a carrier in the dissolution enhancement of poorly water soluble drug, celecoxib., Boll. Chim. Farm. 142 (2003) 76-82.

129.A.M. Avachat, K.N. Gujar, K. V. Wagh, Development and evaluation of tamarind seed xyloglucan-based mucoadhesive buccal films of rizatriptan benzoate, Carbohydr. Polym. 91 (2013) 537-542. doi:10.1016/j.carbpol.2012.08.062.

130.B. Patel, P. Patel, A. Bhosale, S. Hardikar, S. Mutha, G. Chaulang, Evaluation of tamarind seed polysaccharide (TSP) as a mucoadhesive and sustained release component of nifedipine buccoadhesive tablet and comparison with HPMC and $\mathrm{Na}$ CMC, Int. J. PharmTech Res. 1 (2009) 404-410.

131.G. Bangale, G. Shinde, D. Umalkar, Natural mucoadhesive material based buccal tablets of nitrendipine- formulation and in-vitro evaluation, J. Pharm. Res. 4 (2011) 33-38.

132.R.M. Gilhotra, M. Mathur, R. Saroot, N. Gilhotra, D.N. Mishra, Enhancement of miotic potential of pilocarpine gum in-sity gelling ocular dosage form, Acta Pharm. Sci. 52 (2010) 145-154.

133.M. D’Amico, C. Di Filippo, E. Lampa, E. Boldrini, F. Rossi, A. Ruggiero, A. Filippelli, Effects of timolol and of timolol with tamarind seed polysaccharide on intraocular pressure in rabbits, Pharm. Pharmacol. Commun. 5 (1999) 361-364. doi:10.1211/146080899128734974.

134.E. Ghelardi, A. Tavanti, P. Davini, F. Celandroni, S. Salvetti, E. Parisio, E. Boldrini, S. Senesi, M.
Campa, A mucoadhesive polymer extracted from tamarind seed improves the intraocular penetration and efficacy of rufloxacin in topical treatment of experimental bacterial keratitis, Antimicrob. Agents Chemother. 48 (2004) 3396-3401. doi:10.1128/AAC.48.9.3396-3401.2004.

135.M. Rolando, C. Valente, Establishing the tolerability and performance of tamarind seed polysaccharide (TSP) in treating dry eye syndrome: results of a clinical study., BMC Ophthalmol. 7 (2007) 1-8. doi:10.1186/1471-2415-7-5.

136.S. Barabino, M. Rolando, M. Nardi, S. Bonini, P. Aragona, C.E. Traverso, The effect of an artificial tear combining hyaluronic acid and tamarind seeds polysaccharide in patients with moderate dry eye syndrome: A new treatment for dry eye, Eur. J. Ophthalmol. 24 (2013) 173-178. doi:10.5301/ ejo.5000355.

137.F. Dasankoppa, S. Kujur, H.N. Ahmed Sholapur, V. Jamakandi, Design, formulation and evaluation of carboxy methyl tamarind based in situ gelling ophthalmic drug delivery system of dorzolamide hydrochloride, Indian J. Heal. Sci. 9 (2016) 56-66. doi:10.4103/2349-5006.183688.

138.N. Dilbaghi, H. Kaur, M. Ahuja, S. Kumar, Evaluation of tropicamide-loaded tamarind seed xyloglucan nanoaggregates for ophthalmic delivery, Carbohydr. Polym. 94 (2013) 286-291. doi:10.1016/j.carbpol.2013.01.054.

139.H. Kaur, M. Ahuja, S. Kumar, N. Dilbaghi, Carboxymethyl tamarind kernel polysaccharide nanoparticles for ophthalmic drug delivery, Int. J. Biol. Macromol. 50 (2012) 833-839. doi:10.1016/j. ijbiomac.2011.11.017.

140.G.T. Kulkarni, N. Sethi, R. Awasthi, V.K. Pawar, V. Pahuja, Development of ocular delivery system for glaucoma therapy using natural hydrogel as film forming agent and release modifier, Polym. Med. 46 (2016) 25-33. doi:10.17219/pim/63750.

141.M.J. Bhandwalkar, A.M. Avachat, Thermoreversible nasal in situ gel of venlafaxine hydrochloride: Formulation, characterization, and pharmacodynamic evaluation, AAPS PharmSciTech. 14 (2013) 101-110. doi:10.1208/ s12249-012-9893-1.

142.R. Datta, A.K. Bandyopadhyay, A new nasal drug delivery system for diazepam using natural mucoadhesive polysaccharide obtained from tamarind seeds, Saudi Pharm. J. 14 (2006) 115119.

143.A. Kumar, T. Garg, G.S. Sarma, G. Rath, A.K. Goyal, Optimization of combinational intranasal drug delivery system for the management of migraine by using statistical design, Eur. J. 
Pharm. Sci. 70 (2015) 140-151. doi:10.1016/j. ejps.2015.01.012.

144.S.B. Yarragudi, R. Richter, H. Lee, G.F. Walker, A.N. Clarkson, H. Kumar, S.B. Rizwan, Formulation of olfactory-targeted microparticles with tamarind seed polysaccharide to improve nose-to-brain transport of drugs, Carbohydr. Polym. 163 (2017) 216-226. doi:10.1016/j. carbpol.2017.01.044.

145.K.K. Mali, S.C. Dhawale, R. Dias, V. Havaldar, V. Ghorpade, N. Salunkhe, Nasal mucoadhesive in situ gel of granisetron hydrochloride using natural polymers, J. Appl. Pharm. Sci. 5 (2015) 084-093. doi:10.7324/JAPS.2015.50714.

146.M.U. Mishra, J.N. Khandare, Evaluation of tamarind seed polysaccharide as abiodegradable carrier for colon specific drug delivery, Int. J. Pharm. Pharm. Sci. 3 (2011) 139-142.

147.G. Kaur, S. Jain, A.K. Tiwary, Chitosancarboxymethyl tamarind kernel powder interpolymer complexation: investigations for colon drug delivery., Sci. Pharm. 78 (2010) 57-78. doi:10.3797/scipharm.0908-10.

148.G.S. Shaw, D. Biswal, A. B, I. Banerjee, K. Pramanik, A. Anis, K. Pal, Preparation, characterization and assessment of the novel gelatin-tamarind gum/carboxymethyl tamarind gum-based phase-separated films for skin tissue engineering applications, Polym. Plast. Technol. Eng. 56 (2017) 141-152. doi:10.1080/03602559. 2016.1185621 .

149.I. Yadav, V.S.S. Rathnam, Y. Yogalakshmi, S. Chakraborty, I. Banerjee, A. Anis, K. Pal, Synthesis and characterization of polyvinyl alcoholcarboxymethyl tamarind gum based composite films, Carbohydr. Polym. 165 (2017) 159-168. doi:10.1016/j.carbpol.2017.02.026.

150.B.S. Patil, V. Mastiholimath, A.R. Kulkarni,
Novel wound dressing material derived from Crosslinked tamarind seeds polysaccharide: In vitro characterization and wound healing activity, Trends Biomater. Artif. Organs. 25 (2011) 149-153.

151.G. V. Radha, S.M. Naidu, Design of transdermal films of alfuzocin $\mathrm{HCl}$ by using a natural polymer tamarind seed polysaccharide extract, Der Pharm. Lett. 5 (2013) 457-464.

152.K.K. Mali, S.C. Dhawale, R.J. Dias, Microemulsion based bioadhesive gel of itraconazole using tamarind gum: in-vitro and ex-vivo evaluation, Marmara Pharm. J. 21 (2017) 688-700. doi:10.12991/marupj.323593.

153.H.S. Mahajan, S.A. Gundare, Preparation, characterization and pulmonary pharmacokinetics of xyloglucan microspheres as dry powder inhalation, Carbohydr. Polym. 102 (2014) 529536. doi:10.1016/j.carbpol.2013.11.036.

154.F. Suisha, N. Kawasaki, S. Miyazaki, M. Shirakawa, K. Yamatoya, M. Sasaki, D. Attwood, Xyloglucan gels as sustained release vehicles for the intraperitoneal administration of mitomycin C, Int. J. Pharm. 172 (1998) 27-32. doi:10.1016/ S0378-5173(98)00157-4.

155.N.R. Gupta, A.T. Arun Torris, P.P. Wadgaonkar, P.R. Rajamohanan, G. Ducouret, D. Hourdet, C. Creton, M. V. Badiger, Synthesis and characterization of PEPO grafted carboxymethyl guar and carboxymethyl tamarind as new thermo-associating polymers, Carbohydr. Polym. 117 (2015) 331-338. doi:10.1016/j. carbpol.2014.09.073.

156. V. Singh, P. Kumar, Carboxymethyl tamarind gumsilica nanohybrids for effective immobilization of amylase, J. Mol. Catal. B Enzym. 70 (2011) 6773. doi:10.1016/j.molcatb.2011.02.006. 